\title{
Biomarkers of Antioxidant Status, Inflammation, and Cartilage Metabolism Are Affected by Acute Intense Exercise but Not Superoxide Dismutase Supplementation in Horses
}

\author{
Emily D. Lamprecht and Carey A. Williams \\ Department of Animal Sciences, Rutgers the State University, 84 Lipman Drive, New Brunswick, NJ 08901-8525, USA \\ Correspondence should be addressed to Emily D. Lamprecht, emily_lamprecht@cargill.com
}

Received 17 March 2012; Accepted 6 May 2012

Academic Editor: Manfred Lamprecht

Copyright (C) 2012 E. D. Lamprecht and C. A. Williams. This is an open access article distributed under the Creative Commons Attribution License, which permits unrestricted use, distribution, and reproduction in any medium, provided the original work is properly cited.

\begin{abstract}
Objectives were to evaluate effects of (1) repetitive arthrocentesis on biomarkers of inflammation (prostaglandin $\mathrm{E}_{2}, \mathrm{PGE}_{2}$ ) and aggrecan synthesis (chondroitin sulfate-846; CS) in synovial fluid (SF); (2) exercise and superoxide dismutase (SOD) supplementation on biomarkers of inflammation, antioxidant status, and aggrecan synthesis, in horses. Preliminary trial. Standardbreds underwent four arthrocentesis procedures within $48 \mathrm{~h}$ and exhibited elevated CS and no changes in PGE 2 . Exercise trial. this randomized crossover design used twelve Standardbred mares which received either treatment (3000 IU d $\mathrm{d}^{-1}$ oral SOD powder) or placebo (cellulose powder) for $6 \mathrm{wks}$ which culminated with them running a repeated sprint exercise test (RSET). Samples were collected before (PRE), during (PEAK), and following exercise (POST). Exercise resulted in increased $(P<0.05)$ antioxidant defenses including erythrocyte SOD, total glutathione, glutathione peroxidase, gene transcripts for interferon-gamma, interleukin-10, and interleukin- $1 \beta$ in blood, and decreased plasma nitric oxide. Exercise increased $(P<0.05)$ SF CS and adjusted$\mathrm{PGE}_{2}$, and higher $(P<0.05) \mathrm{CS}$ and $\mathrm{PGE}_{2}$ were found in hock versus carpus joints. No treatment effects were detected. Results suggest normal adaptive responses likely due to exercise-induced tissue microdamage and oxidative stress. Additional research is needed to identify benefit(s) of SOD supplementation in horses.
\end{abstract}

\section{Introduction}

Equine athletes suffer from challenges of the immune system and inflammation related to exercise [1-4]. Intense physical activity has been shown to induce subclinical tissue damage and a subsequent immune response involving the upregulation of inflammatory mediators termed cytokines. Exercise-induced increases in cytokine transcripts including tumor necrosis factor alpha (TNF $\alpha$ ), interleukin-1 beta (IL$1 \beta)$, interferon gamma (IFN $\gamma$ ), interleukin-6 (IL-6), and interleukin-10 (IL-10) are comparable to that of an acute phase immune response and have been demonstrated in horses $[5,6]$. Furthermore, inflammatory processes have also been associated with redox imbalances favoring prooxidants, resulting in oxidative stress [7]. Exercise-induced increases in the generation of reactive oxygen species (ROS), including, free radicals have also been demonstrated in horses $[6,8-12]$. Over exaggerated or sustained responses to intense exhaustive exercise may set the stage for a chronic inflammatory and/or an immunosuppressed state and a predisposition to infection, poor physical performance, and/or onset of chronic diseases [13, 14].

Specifically, degenerative joint disease is a major concern to the equine industry. Joint discomfort in horses is the most common cause of lameness, diminished athletic performance and quality of life, economic burden, and animal loss [15-18]. Due to high rates of morbidity and mortality related to arthropathies, biomarkers indicative of early changes related to the development of joint disease have been identified, providing an opportunity to detect and mitigate the disease process early on. Prostaglandin $E_{2}$ $\left(\mathrm{PGE}_{2}\right)$ is a prostanoid important for the maintenance of local homeostasis, mediation of inflammation, and sensitization to pain $[19,20]$. Elevated $\mathrm{PGE}_{2}$ concentration in 
synovial fluid is considered an indicator of synovitis [21, 22] and a predictor of equine joint disease [2]. The CS-846 epitope (CS) is found on fragments of newly synthesized aggrecan that have been released from the cartilage matrix [23] and can serve as a biomarker for cartilage metabolism, specifically aggrecan synthesis, in equine joints $[21,22,24]$.

Identification of nutritional interventions which are effective in supporting resilience to exercise-induced inflammation and oxidative stress is needed. Most nutritional supplements are intended to decrease onset, severity or progression of disease symptoms, but lack controlled research. With verification of safety and efficacy in the target specie, nutritional interventions may provide practical and less cost-prohibitive options compared to other medical or pharmacological therapies $[25,26]$. Furthermore, the use of orally available antioxidant enzymes may have an advantage over nonenzymatic supplements, because they catalyze the detoxification of their ROS substrates in a disproportionate manner, instead of getting stoichiometrically consumed like exogenous antioxidant substrates [26].

Superoxide dismutases (SOD) are enzymatic antioxidant defenses which catalyze the dismutation of superoxide ions into oxygen and hydrogen peroxide. Studies reporting the successful use of antioxidant enzymes as dietary interventions are increasing. Furthermore, there are several reports indicating that supplementation with exogenous SOD is effective in reducing proinflammatory cytokines and inhibiting neutrophil infiltration to sites of tissue damage in several inflammation models $[27,28]$. Exogenous SOD has been used in various forms, as an oral supplement [29-31], topical treatment [32], and injectable therapy [33, 34]. Effectiveness in modifying systemic inflammatory responses, antioxidant status, and chondroprotective effects in diarthrodial joints, following oral supplementation in horses, remains to be investigated. Therefore, the purpose of this study was to evaluate the effect(s) of oral SOD supplementation in horses following intense exhaustive exercise. Objectives of the current study were as follows: (1) to evaluate the effects of repeated arthrocentesis within a $48 \mathrm{~h}$ time frame on markers of inflammation and cartilage metabolism in synovial fluid of healthy horses at rest and (2) to evaluate the effects of a single bout of intense exhaustive treadmill exercise and exogenous SOD supplementation on biomarkers of inflammation, antioxidant status, and anabolic cartilage metabolism in healthy horses.

\section{Materials and Methods}

2.1. Subjects. A sample of 12 healthy, unfit Standardbred mares aged $8 \pm 1 \mathrm{yr}$, weighing $513.8 \pm 16.7 \mathrm{~kg}$, with lameness scores of $0.3 \pm 0.1$ (on a scale of $0-5$, with 5 being nonweight bearing; [35]), body condition scores of $5.3 \pm 0.1$ (on a scale of $1-9$, with 1 being emaciated and 9 being morbidly obese; [36]), and per cent body fat at $20.7 \pm$ $1.8 \%$ [37] were used in this study. Mares were housed in New Jersey at the Rutgers University Equine Exercise Physiology Laboratory on 2-acre exercise lots and were provided ad libitum access to moderate quality grass hay, water, and salt. They also received $1 \mathrm{~kg}$ of a $10 \%$ crude protein sweet feed (Nutrena Vitality, Cargill Inc., Minneapolis, MN, USA) twice daily to meet maintenance requirements. All animal procedures described herein have been approved by the Rutgers University Institutional Animal Care and Use Committee. Aspects of the experimental design were approved retrospectively.

2.2. Preliminary Trial. The objective of this preliminary trial was to evaluate effects of repeated arthrocentesis within a $48 \mathrm{~h}$ time frame on a marker of inflammation and anabolic cartilage metabolism in synovial fluid of healthy horses at rest. Synovial fluid samples were collected from 6 randomly selected mares out of the sample population previously described. Aseptic arthrocentesis was performed on the same radiocarpal joint space in each horse on four occasions within a $48 \mathrm{~h}$ time frame at the following intervals-initial joint tap $\left(T_{1}\right)$, second joint tap $24 \mathrm{~h}$ following the initial tap $\left(T_{2}\right)$, third tap $26 \mathrm{~h}$ following the initial tap $\left(T_{3}\right)$, and a fourth tap $48 \mathrm{~h}$ following the initial tap $\left(T_{4}\right)$. Mares were mildly sedated with $0.3-0.5 \mathrm{~mL}$ of detomidine hydrochloride (10 $\mathrm{mg} \mathrm{mL}^{-1}$ ) intravenously, $10 \mathrm{~min}$ prior to each arthrocentesis procedure. The synovial fluid was initially collected into sterile syringes using sterile 20 gauge one inch hypodermic needles, and then immediately transferred to prechilled $10 \mathrm{~mL}$ tubes containing ethylenediaminetetraacetic acid (EDTA) and placed on ice. Samples were centrifuged for $20 \mathrm{~min}$ at $1500 \times \mathrm{g}$ to remove any cellular debris, aliquoted and stored at $-80^{\circ} \mathrm{C}$ for later analysis of $\mathrm{PGE}_{2}$ (R\&D Systems Parameter High-Sensitivity $\mathrm{PGE}_{2}$ Assay, Minneapolis, MN, USA; Intra-assay CV $=18.0 \%$ Interassay $C V=13.9 \%$; [38]) and CS (Aggrecan CS-846 Epitope ELISA, IBEX Pharmaceuticals Inc., Montreal, Quebec, Canada; Intra-assay $\mathrm{CV}=3.1 \%$; Interassay $\mathrm{CV}=8.1 \%$; [24]) according to manufacturer's instructions.

\subsection{Exercise Trial}

Design/Supplement. This study was conducted as a placebo controlled randomized crossover design to evaluate the effects of a single bout of intense exhaustive treadmill exercise and exogenous SOD supplementation on biomarkers of inflammation, antioxidant status, and anabolic cartilage metabolism in healthy horses. Mares were randomly assigned to either a treatment group (TRT) or placebo group (CON). The TRT group received $3 \mathrm{~g} / \mathrm{d}$ ( 3000 IU of enzyme activity) of a proprietary oral formulation of SOD powder extracted from cantaloupe melon and chemically combined with wheat gliadin (vegetal hydrophobic biopolymer). The SOD supplement was verified prior to the study, to provide a minimum of $1000 \mathrm{IU}$ of enzyme activity per gram of powder, using a nitro blue tetrazolium reduction method previously described [39]. The CON group received $3 \mathrm{~g} / \mathrm{d}$ of a microcrystalline cellulose powder. Both TRT and CON groups received their supplement top dressed on their morning grain ration and all investigators were blind to the treatments. The initial phase of the study consisted of a $42 \mathrm{~d}$ supplementation period which concluded with 
a repeated sprint exercise test (RSET), previously determined to influence biomarkers of inflammation and antioxidant status in horses [6]. Mares then completed a $42 \mathrm{~d}$ washout period, the experimental groups were crossed over and an identical $42 \mathrm{~d}$ supplementation period and RSET were completed. Before each phase of the study, standardized methods were used to evaluate each mare for body condition [36], orthopedic soundness [35], and per cent body fat [37].

Exercise Protocol. The RSET lasted an average of $18.4 \pm$ $0.7 \mathrm{~min}$ and began with $2.5 \mathrm{~min}$ of walking at $1.5 \mathrm{~m} \mathrm{~s}^{-1}$ followed by $4 \mathrm{~min}$ of trotting at $4 \mathrm{~m} \mathrm{~s}^{-1}$. Following warm up, mares completed 2 min sprints at $7,8,9$, and $10 \mathrm{~m} \mathrm{~s}^{-1}$ with 2 min of walk at $1.5 \mathrm{~m} \mathrm{~s}^{-1}$ between each sprint $[40,41]$. Mares ran to fatigue or until the test was completed, at which time they spent $1 \mathrm{~min}$ walking at $1.5 \mathrm{~m} \mathrm{~s}^{-1}$. Fatigue was defined as an inability of the mares to keep up with the treadmill despite humane encouragement.

\subsection{Sampling and Analysis.}

Synovial Fluid. Samples were taken $24 \mathrm{~h}$ before exercise (PRE), $30 \mathrm{~min}, 2 \mathrm{~h}$, and $24 \mathrm{~h}$ after exercise (POST). Samples were collected via aseptic arthrocentesis from one radiocarpal and one tibiotarsal joint space as described above for the preliminary trial, and placed into prechilled $10 \mathrm{~mL}$ tubes containing EDTA and immediately placed back on ice. The SF was centrifuged for $20 \mathrm{~min}$ at $1500 \times \mathrm{g}$ to remove any cellular debris, aliquoted and stored at $-80^{\circ} \mathrm{C}$ for later analysis of CS and $\mathrm{PGE}_{2}$ using commercial ELISA kits, as described above.

Venous Blood. Samples were collected relative to the RSET, before exercise (PRE), at completion of the sprint portion of the RSET (PEAK), $30 \mathrm{~min}, 2,4,24$, and $36 \mathrm{~h}$ after exercise (POST). Blood was collected using an indwelling jugular catheter and placed into prechilled $10 \mathrm{~mL}$ tubes containing sodium heparin, another $10 \mathrm{~mL}$ tube containing EDTA, and $10 \mathrm{~mL}$ serum separator tubes containing clot activator and gel for serum separation (Vacutainer, Becton Dickinson, Franklin Lakes, NJ, USA). Heparinized tubes were placed back on ice and immediately analyzed for packed cell volume (Hct) using microhematocrit technique (CritSpin S-120, Iris Sample Processing, Westwood, MA, USA) and were centrifuged for $10 \mathrm{~min}$ at $1500 \times \mathrm{g}$ at $4^{\circ} \mathrm{C}$. The plasma fraction was then analyzed for total protein (TP) using digital refractometry (Palm Abbe Veterinary Refractometer, MISCO Inc., Cleveland, Ohio, USA). Serum tubes remained at room temperature for approximately $1 \mathrm{~h}$ to allow for blood clotting and were centrifuged for $20 \mathrm{~min}$ at $1500 \times \mathrm{g}$ at $10^{\circ} \mathrm{C}$. Plasma and serum fractions were aliquoted and frozen at $-80^{\circ} \mathrm{C}$ for later analysis. Blood components were analyzed for plasma lactate (LA; YSI Sport 1500, YSI Inc. Life Sciences, Yellow Springs, Ohio, USA; intra-assay CV $=0.79 \%$; interassay CV $=0.72 \%$ ), serum creatine kinase (CK; VetTest CK Slides; VetTest 8008 analyzer, IDEXX Laboratories Inc., Westbrook, MA, USA; intra-assay CV $=1.39 \%$; interassay CV $=1.29 \%$ ), plasma total nitrite as an indicator of nitric oxide (NO;
BioAssay Systems, Hayward, CA, USA; intra-assay CV = $4.7 \%$; interassay $\mathrm{CV}=7.96 \%$; [42]), and serum CS (as described above for the preliminary trial). All assays were run according to manufacturer's instructions.

Erythrocyte Lysate. For assays utilizing erythrocyte lysate, $500 \mu \mathrm{L}$ whole blood from a sodium heparin collection tube was transferred to a microcentrifuge tube and was centrifuged at $2500 \times \mathrm{g}$ for $5 \mathrm{~min}$ at $4^{\circ} \mathrm{C}$. The plasma supernatant was discarded and the remaining erythrocytes were washed with $500 \mu \mathrm{L}$ of sterile $0.9 \%$ sodium chloride solution, thoroughly vortexed and centrifuged a second time as described above. The saline supernatant was carefully removed and discarded from the sample, and the remaining erythrocytes were lysed with $1 \mathrm{~mL}$ of ice-cold distilled deionized water. Erythrocyte lysate was aliquoted and stored at $-80^{\circ} \mathrm{C}$ within $20 \mathrm{~min}$ of collection, for later analysis of SOD activity (SOD Assay Kit-WST, Dojindo Molecular Technologies Inc., Rockville, MD, USA; interassay CV = 13.7\%; [43]), hemoglobin concentration (QuantiChrom 92 Hemoglobin Assay Kit, BioAssay Systems, Hayward, CA, USA; [44]), glutathione peroxidase activity (GPx; OxisResearch, Foster City, CA, USA; intraassay $\mathrm{CV}=0.99 \%$; interassay $\mathrm{CV}=$ $10.8 \%$; [45]), and total glutathione (GSH-T; OxisResearch, Foster City, CA, USA; intraassay CV $=1.1 \%$; interassay CV = $1.2 \%$; [46]), all according to manufacturer's instructions.

RNA Collection. Blood was also collected by means of jugular puncture into PAXgene blood RNA collection tubes (Qiagen/Becton Dickinson, Valencia, CA, USA) containing quaternary amine surfactants at PRE, $30 \mathrm{~min}, 2 \mathrm{~h}$, and $24 \mathrm{~h}$ POST sample times. Total RNA was collected from $2.5 \mathrm{~mL}$ of whole blood according to manufacturer's instructions and the RNA was quantified using a spectrophotometer (Biophotometer, Eppendorf, Westbury, NY, USA). The RNA purity and quantity in each extraction were found to be sufficient for gene expression analysis and amplification efficiencies were between 1.8 and 2.2. A detailed description of RNA preparation, reverse transcription, and amplification was described previously [47]. Relative quantification (2$\Delta \Delta C T$ method) was used to analyze the changes in gene expression [48, 49]. Cytokine (target) gene expression was normalized to that of the endogenous control gene betaglucuronidase ( $\beta$-GUS) and fold changes in target gene expression were calculated relative to a calibrator sample (mean resting baseline) within each data set. Amplification efficiency variation was taken into account and corrected for using the LinReg 7.0 software [50]. The following cytokine transcripts were measured: tumor necrosis factor alpha (TNF $\alpha$; pro-inflammatory), interleukin-1 beta (IL- $1 \beta$; proinflammatory), interferon gamma (IFN $\gamma$; immunomodulatory), interleukin-6 (IL-6; multifunctional), and interleukin10 (IL-10; anti-inflammatory). Equine cytokine primer and probe sequences and PCR amplicon fragment sizes were previously published [6].

Statistical Analysis. For the preliminary trial, data are presented as the mean \pm SE and analyzed using a MIXED model 
TABle 1: Preliminary trial. synovial fluid concentrations of chondroitin sulfate-846 (CS) and prostaglandin $\mathrm{E}_{2}\left(\mathrm{PGE}_{2}\right)$ during 4 repeated arthrocentesis procedures in a $48 \mathrm{~h}$ time frame at the following intervals: initial joint tap $\left(T_{1}\right), 24 \mathrm{~h}$ following $T_{1}\left(T_{2}\right), 26 \mathrm{~h}$ after $T_{1}\left(T_{3}\right)$, and $48 \mathrm{~h}$ following $T_{1}\left(T_{4}\right)$, in carpus joints. Data are presented as mean $\pm \mathrm{SE}$. Means without a common superscript differ $(P<0.05)$.

\begin{tabular}{lcccc}
\hline Variable & $T_{1}$ & $T_{2}$ & $T_{3}$ & $T_{4}$ \\
\hline $\mathrm{CS}, \mathrm{ng} \mathrm{mL}^{-1}$ & $5214.7 \pm 717.5^{\mathrm{a}}$ & $5842.9 \pm 784.9^{\mathrm{ab}}$ & $5225.1 \pm 679.3^{\mathrm{a}}$ & $6643.5 \pm 1247^{\mathrm{b}}$ \\
$\mathrm{PGE}_{2}, \mathrm{pg} \mathrm{mL}^{-1}$ & $802.8 \pm 249.2$ & $1119.2 \pm 279.1$ & $579.2 \pm 171.7$ & $1188.9 \pm 245.6$ \\
\hline
\end{tabular}

TABLE 2: Exercise trial. hematocrit (Hct), plasma total protein (TP), plasma lactate (LA), and serum creatine kinase (CK) concentrations before (Pre), during (Peak), $30 \mathrm{~min}, 2 \mathrm{~h}, 4 \mathrm{~h}, 24 \mathrm{~h}$, and $36 \mathrm{~h}$ after exercise (Post). Data are presented as means $\pm \mathrm{SE}$; different superscripts denote differences within rows at $P<0.05$.

\begin{tabular}{|c|c|c|c|c|c|c|c|}
\hline Variable & Pre & Peak & $30 \mathrm{~min}$ POST & $2 \mathrm{~h}$ POST & $4 \mathrm{~h}$ POST & $24 \mathrm{~h}$ POST & $36 \mathrm{~h}$ POST \\
\hline Hct, \% & $36.5 \pm 0.9^{\mathrm{a}}$ & $54.1 \pm 1.2^{\mathrm{b}}$ & $45.2 \pm 1.2^{\mathrm{c}}$ & $40.4 \pm 1.1^{\mathrm{d}}$ & $35.4 \pm 1.1^{\mathrm{a}}$ & $40.1 \pm 1.2^{\mathrm{d}}$ & $40.1 \pm 1.0^{\mathrm{d}}$ \\
\hline $\mathrm{TP}, \mathrm{g} \mathrm{dL}^{-1}$ & $6.3 \pm 0.1^{\mathrm{a}}$ & $7.5 \pm 0.2^{\mathrm{b}}$ & $6.5 \pm 0.1^{c}$ & $6.3 \pm 0.1^{\mathrm{a}}$ & $6.2 \pm 0.1^{\mathrm{a}}$ & $6.6 \pm 0.1^{c}$ & $6.6 \pm 0.1^{c}$ \\
\hline $\mathrm{LA}, \mathrm{mmol} \mathrm{L}^{-1}$ & $0.7 \pm 0.1^{\mathrm{a}}$ & $23.4 \pm 2.1^{\mathrm{b}}$ & $14.0 \pm 2.1^{\mathrm{c}}$ & $2.2 \pm 0.3^{\mathrm{a}}$ & $1.0 \pm 0.1^{\mathrm{a}}$ & $0.7 \pm 0.1^{\mathrm{a}}$ & $0.8 \pm 0.1^{\mathrm{a}}$ \\
\hline $\mathrm{CK}, \mathrm{U} \mathrm{L}^{-1}$ & $205.6 \pm 15.0^{\mathrm{a}}$ & $276.7 \pm 21.9^{b}$ & $255.8 \pm 20.6^{c}$ & $254.3 \pm 21.2^{\mathrm{c}}$ & $255.7 \pm 22.3^{c}$ & $206.3 \pm 14.3^{\mathrm{a}}$ & $228.4 \pm 18.1^{\mathrm{d}}$ \\
\hline
\end{tabular}

ANOVA with repeated measures in SAS to evaluate effects of repeated arthrocentesis sampling. Significant main effects were further analyzed using Tukey-Kramer post hoc analysis to further elucidate significant changes as inferred when $P<$ 0.05 .

For the exercise trial, cytokine data are presented as relative mRNA transcripts (RMT) or the mean fold changes in target gene expression normalized to an endogenous control gene ( $\beta$-GUS) and relative to that of a calibrator sample (resting, presupplementation baseline) in response to intense exercise \pm SE. All other data are summarized as the mean \pm SE. Data were analyzed using a MIXED model ANOVA with repeated measures in SAS 9.1 to evaluate effects of SOD supplementation (TRT versus CON), acute exercise (as sample time), joint space (as carpus and hock; for synovial fluid parameters), and interactions. Horse was nested within treatment as the subject, and sample time was designated as the repeated effect. The Satterthwaite approximation of standard errors was utilized to account for any unequal variances. Significant main effects were further analyzed using Tukey-Kramer post hoc analysis to further elucidate significant changes as inferred when $P<$ 0.05. Pearson's product moment correlation was used to test for associations between the variables measured and only significant associations were reported.

\section{Results}

3.1. Preliminary Trial. Effect of repeated arthrocentesis was detected for CS $(P=0.04$; Table 1$)$ where synovial fluid concentrations were higher $(P<0.05)$ at $\left(T_{4}\right)$ when compared to $\left(T_{1}\right)$ and $\left(T_{3}\right)$. No differences $(P>0.05)$ in concentrations of CS were detected between $\left(T_{4}\right)$ and $\left(T_{2}\right)$. Differences between sampling times for $\mathrm{PGE}_{2}(P>0.05$; Table 1) were not detected.

\subsection{Exercise Trial}

Response to Exercise. There were no TRT effects detected for any parameter measured $(P>0.05)$. A main effect of exercise
$(P<0.0001)$ was detected for Hct, plasma TP, plasma LA, and serum $\mathrm{CK}$, where maximal values occurred at PEAK during exercise (Table 2).

Biomarkers of Antioxidant Status. The RSET did influence SOD activity $(P=0.002)$, GPx activity $(P<0.0001)$, GSH$\mathrm{T}(P<0.0001)$, and NO $(P=0.0002)$. Erythrocyte SOD activity increased from PRE to PEAK $(P=0.001)$ followed by a decrease $(P=0.006)$ to preexercise activity at $30 \mathrm{~min}$ POST (Figure 1(a)). Erythrocyte GPx activity was higher $(P<0.01$; Figure 1(b)) at PEAK when compared to other time points, and returned to preexercise activity by $30 \mathrm{~min}$ POST. Similar to GPx, erythrocyte GSH-T was also highest $(P<0.001$; Figure $1(\mathrm{c}))$ at PEAK compared to other samples times, and gradually returned to preexercise values by $4 \mathrm{~h}$ POST. Plasma NO decreased ( $P=0.002$; Figure $1(\mathrm{~d}))$ from $30 \mathrm{~min}$ POST to $24 \mathrm{~h}$ POST and returned to PRE values at $36 \mathrm{~h}$ POST.

Biomarkers of Systemic Inflammatory Response. The RSET influenced IFN $\gamma(P=0.007)$, IL-1 $\beta(P=0.0002)$, and IL$10(P=0.007)$ transcripts; however, there was no effect of sample time on IL-6 or TNF $\alpha$ gene expression $(P>0.05)$. Interferon gamma transcripts increased $(P=0.03$; Table 3$)$ from PRE to PEAK and decreased $(P=0.01)$ to preexercise levels at $2 \mathrm{~h}$ POST. Gene expression for IL- $1 \beta$ was higher at $2 \mathrm{~h}$ POST $(P<0.005$; Table 3$)$ when compared to PRE, $30 \mathrm{~min}$ and $24 \mathrm{~h}$ POST samples. Transcripts for IL-10 also tended to increase $(P=0.08$; Table 3$)$ from PRE to PEAK and then decreased $(P=0.005)$ from PEAK to $24 \mathrm{~h}$ POST returning to pre-exercise values. Correlations were detected and can be found in Table 4 .

Biomarkers of Joint Health. For CS concentrations, there were main effects of exercise $(P=0.009)$ in serum samples, as well as main effects of exercise $(P<0.0001)$ and joint $(P<0.0001)$ for CS in synovial fluid. Further data analysis revealed lower $(P<0.05)$ serum concentrations of CS at $30 \mathrm{~min}$ and $2 \mathrm{~h}$ POST samples when compared to $24 \mathrm{~h}$ POST. 


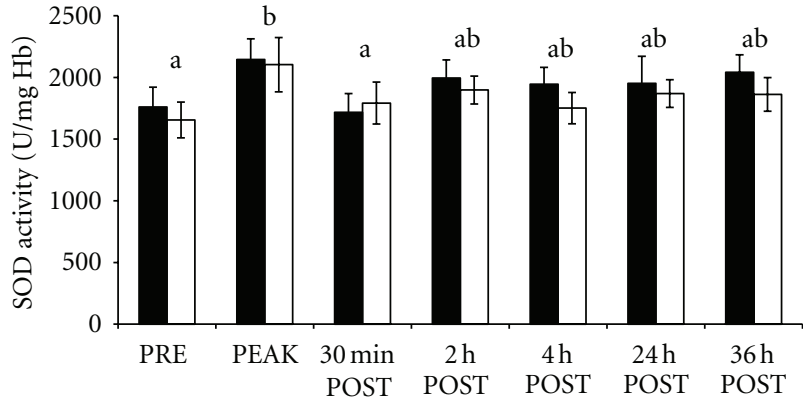

(A)

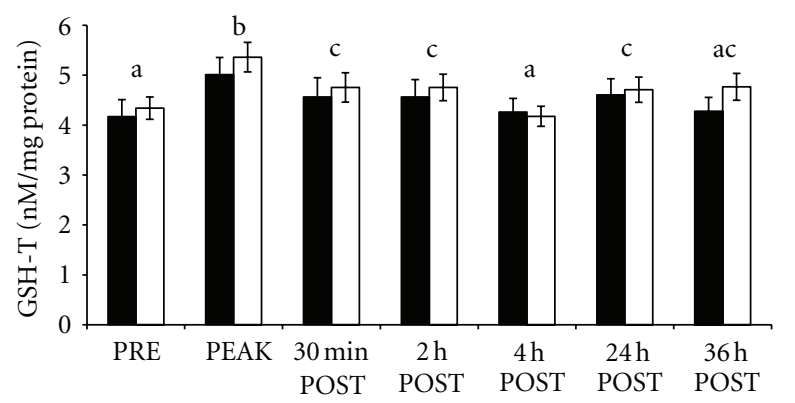

(C)

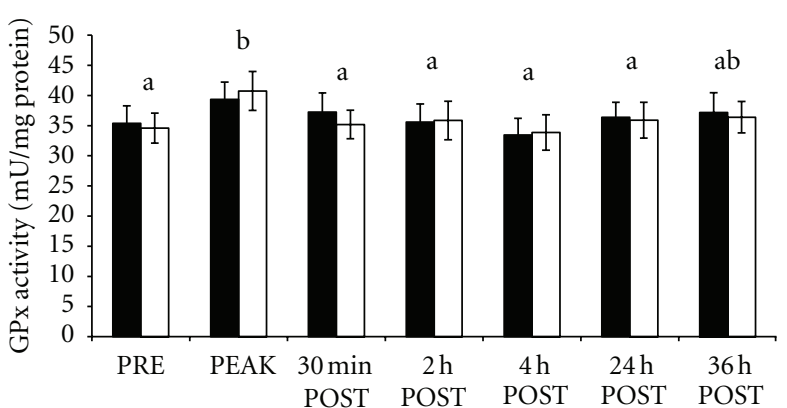

(B)

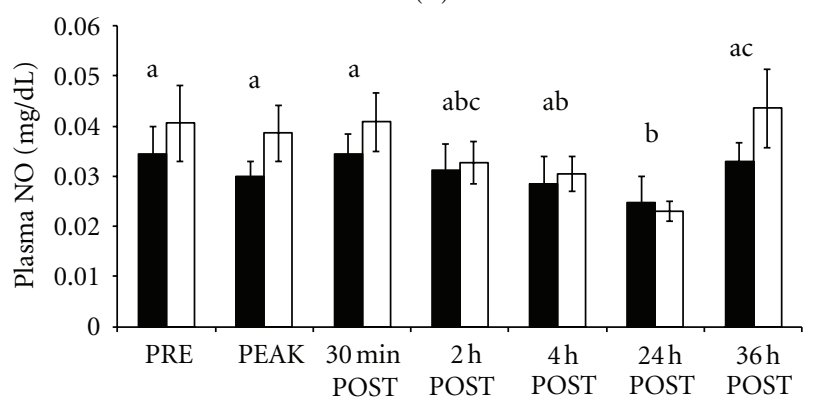

(D)

FIGURe 1: (A-D). exercise trial: erythrocyte superoxide dismutase activity (SOD; A), glutathione peroxidase activity (GPx; B), total glutathione (GSH-T; C), and plasma total nitrite as an indirect biomarker of nitric oxide (NO; D) before (PRE), during (PEAK), 30 min, $2 \mathrm{~h}, 4 \mathrm{~h}, 24 \mathrm{~h}$, and $36 \mathrm{~h}$ after exercise (POST). Solid bars represent TRT and clear bars CON groups. Data are presented as mean \pm SE; means without a common superscript differ $(P<0.05)$ between sample times.

TABLE 3: Exercise trial: interferon $\gamma$ (IFN $\gamma$ ), interleukin-1 $\beta$ (IL-1 $\beta$ ), and interleukin-10 (IL-10) relative mRNA transcript (RMT) in peripheral blood of Standardbred mares before exercise (Pre), $30 \mathrm{~min}$ after exercise (Post), $2 \mathrm{~h}$, and $24 \mathrm{~h}$ Post. qRT-PCR data are presented as the mean fold change in target gene expression \pm SE. Means without a common superscript differ between sample times $\left({ }^{\mathrm{a}, \mathrm{b}} P<0.05 ;{ }^{\mathrm{x}, \mathrm{y}} P<0.1\right)$. No TRT effects were detected.

\begin{tabular}{|c|c|c|c|c|c|c|c|c|}
\hline & \multicolumn{2}{|c|}{ Pre } & \multicolumn{2}{|c|}{30 min Post } & \multicolumn{2}{|c|}{$2 \mathrm{~h}$ Post } & \multicolumn{2}{|c|}{$24 \mathrm{~h}$ Post } \\
\hline & TRT & $\mathrm{CON}$ & TRT & $\mathrm{CON}$ & TRT & $\mathrm{CON}$ & TRT & $\mathrm{CON}$ \\
\hline IFN $\gamma$, RMT & $1.1 \pm 0.2^{\mathrm{a}}$ & $1.2 \pm 0.2^{\mathrm{a}}$ & $2.7 \pm 1.1^{b}$ & $3.6 \pm 1.9^{b}$ & $0.9 \pm 0.1^{\mathrm{a}}$ & $1.1 \pm 0.3^{\mathrm{a}}$ & $1.3 \pm 0.3^{\mathrm{a}}$ & $1.2 \pm 0.3^{\mathrm{a}}$ \\
\hline IL- $1 \beta$, RMT & $1.2 \pm 0.2^{\mathrm{a}}$ & $2.1 \pm 1.0^{\mathrm{a}}$ & $1.1 \pm 0.2^{\mathrm{a}}$ & $1.2 \pm 0.2^{\mathrm{a}}$ & $8.2 \pm 3.3^{b}$ & $3.8 \pm 0.3^{b}$ & $1.4 \pm 0.2^{\mathrm{a}}$ & $1.8 \pm 0.2^{\mathrm{a}}$ \\
\hline IL-10, RMT & $1.6 \pm 0.5^{\mathrm{x}}$ & $2.0 \pm 0.5^{\mathrm{x}}$ & $3.5 \pm 1.6^{y}$ & $2.5 \pm 0.7^{y}$ & $2.3 \pm 0.6^{\mathrm{x}}$ & $2.3 \pm 0.8^{\mathrm{x}}$ & $1.4 \pm 0.4^{\mathrm{x}}$ & $1.2 \pm 0.3^{\mathrm{x}}$ \\
\hline
\end{tabular}

Synovial fluid concentrations of CS were elevated $(P<0.01)$ at $30 \mathrm{~min}$ POST compared to PRE and $2 \mathrm{~h}$ POST samples, and when compared to all other sample times, synovial fluid CS was higher $(P<0.0001)$ at $24 \mathrm{~h}$ POST (Figure $2(\mathrm{a}))$. Hock joints were found to have higher $(P<0.0001)$ concentrations of CS when compared to carpus joints (Figure 2(a)).

Main effects for $\mathrm{PGE}_{2}$ concentrations in synovial fluid were not detected $(P>0.05)$; however, after adjusting the data by subtracting the PRE value from each POST value, and evaluating changes relative to pre-exercise values, effects of exercise $(P=0.03)$ and joint $(P=0.04)$ were detected (Figure 2(b)). The relative increase in $\mathrm{PGE}_{2}$ at $24 \mathrm{~h}$ POST was greater than that at PRE $(P=0.03)$ and demonstrated a trend for being greater $(P=0.08)$ when compared to relative changes at the $30 \mathrm{~min}$ POST sample time (Figure 2(b)). Similar to synovial fluid CS concentrations, there were greater relative increases $(P=0.04)$ in $\mathrm{PGE}_{2}$ concentrations in hock joints when compared to carpus joints (Figure 2(b)).

\section{Discussion}

4.1. Effect of Repeated Arthrocentesis. The impact of repeated arthrocentesis on biomarkers of inflammation and joint health are conflicting in the literature. Therefore, the primary objective of the preliminary trial was to identify possible confounding factors arising from the specific repeated arthrocentesis protocol that was implemented in the subsequent exercise trial, in a sample population of healthy horses. Data from this trial indicated that repeated synovial fluid sampling did not elicit a detectable inflammatory response based upon statistically similar $\mathrm{PGE}_{2}$ concentrations, but may have mildly impacted aggrecan turnover as evidenced by elevated CS at the last sample time. These data are in partial contrast to a previous study which demonstrated increases in synovial fluid concentrations of $\mathrm{PGE}_{2}$ and nitric oxide following 2 consecutive joint taps with a 12-hour interval between taps, when compared to baseline values [51]. Increases in 


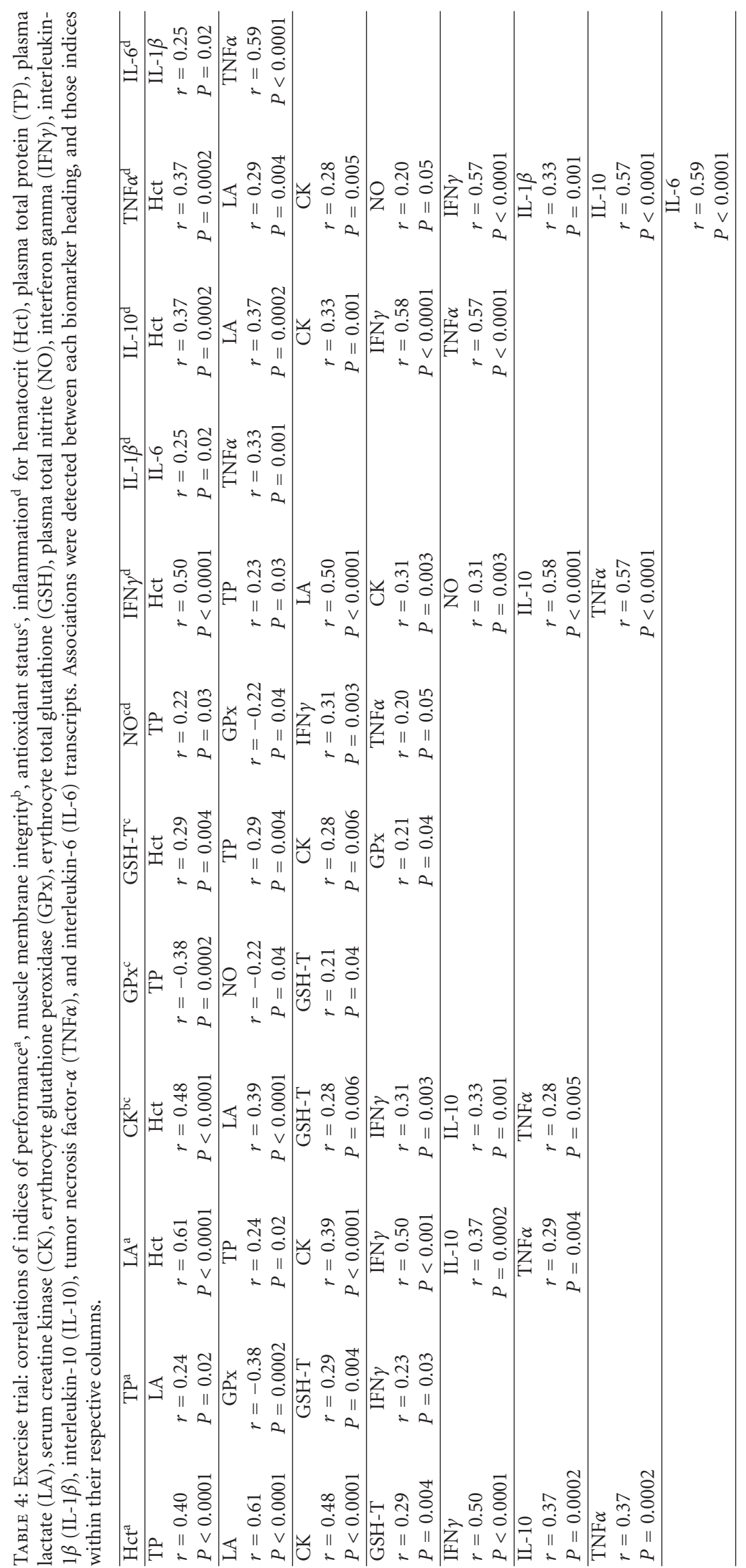




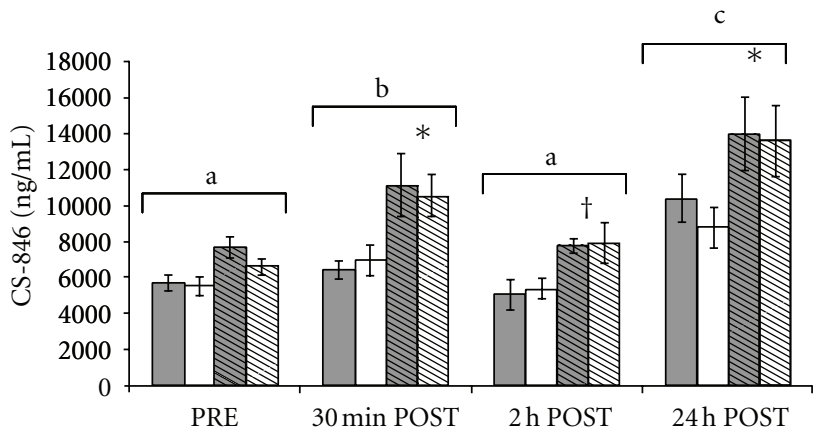

(A)

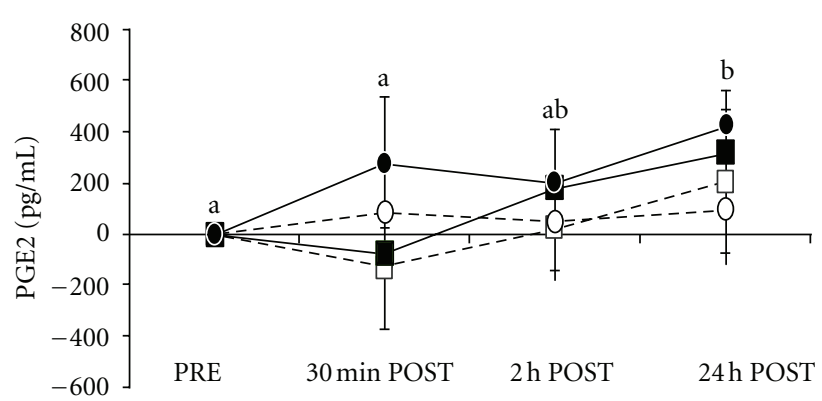

(B)

FIgure 2: (A, B). Exercise trial: (A) synovial fluid concentrations of chondroitin sulfate-846 epitope (CS-846; A) before exercise (PRE), $30 \mathrm{~min}, 2 \mathrm{~h}$, and $24 \mathrm{~h}$ following exercise (POST). Open bars represent carpus samples, hashed bars represent hock samples, grey bars represent TRT groups, and white bars represent CON groups. Data are presented as mean \pm SE. (B) Relative synovial fluid concentrations of PGE 2 $30 \mathrm{~min}, 2 \mathrm{~h}$, and $24 \mathrm{~h}$ following exercise (POST) compared to samples collected $24 \mathrm{~h}$ prior to exercise (PRE). Squares indicate TRT group, circles indicate CON group, solid shapes indicate hock samples, and open shapes indicate carpus samples. Data were adjusted by subtracting $\mathrm{PRE}$ values from each sample time, and are presented as mean relative change from PRE \pm SE. Different superscripts denote relative increases from PRE values. Means without a common superscript differ $(P<0.05)$ between sample times; *infers significant differences $(P<0.05)$ and ${ }^{\dagger}$ infers a trend towards significant differences $(P<0.1)$ between joint spaces within a sample time. Greater increases $(P=0.04)$ in $P G E_{2}$ in hock joints compared to carpus joints were detected.

glycosaminoglycans (GAG) were also detected in radiocarpal and tarsocrural joints after 2 consecutive taps with a 60 hour interval between taps, in mature healthy horses. Another study reported increased matrix metalloproteinase1 , a biomarker for tissue remodeling, in equine synovial fluid, following repeated arthrocentesis within a $60 \mathrm{~h}$ time-frame [52]. These findings are in partial contrast to additional reports in the literature. A previous study [6] did not find a repetitive arthrocentesis protocol, similar to the present trial's, to modulate synovial fluid concentrations of nitric oxide, in radiocarpal and tibiotarsal joints of mature, healthy mares following intense exhaustive treadmill exercise. Another study reported no effect of repeated synovial fluid sampling (4 taps over 10 days with intervals ranging from $12 \mathrm{~h}$ to $168 \mathrm{~h}$ between taps) on the pro-inflammatory regulator TNF $\alpha$, in synovial fluid of normal equine joints [53]. Furthermore, a study where healthy horses underwent weekly synovial fluid aspiration for a total of $13 \mathrm{wks}$ did not report evidence of repeated sampling effects on keratin sulfate or CS in control radiocarpal joints [54]. Authors of a similar study, during which healthy young horses underwent repeated arthrocentesis for several weeks, concluded that any effects of the repeated synovial fluid sampling were minor and most likely did not confound experimental data [22]. Relative to the preliminary trial, the specific arthrocentesis protocol that was executed did not appear to influence $\mathrm{PGE}_{2}$ at any sample time, although aggrecan synthesis may have been impacted, indicated by mildly elevated CS concentrations at the last sampling time, and should be taken into consideration when interpreting similar data from the exercise trial.

4.2. Response to Exercise. The RSET was strenuous enough to elicit increases in muscle enzymes, pro- and antiinflammatory cytokine gene transcripts, as well as markers of antioxidant status, discussed below. Normal increases in Hct and TP from PRE to PEAK samples were expected findings in the present study and are consistent with previous studies evaluating hematologic and plasma biochemical measurements in exercising horses $[55,56]$.

The LA increase during and after exercise in the present study indicates that mares were working at a velocity consistently above their anaerobic threshold and in a state where the lactate efflux mechanism was saturated. Lactate response in the present study was positively correlated with CK, pro-inflammatory cytokine IFN $\gamma$ and TNF $\alpha$ transcripts, as well as the anti-inflammatory cytokine IL-10, which further demonstrates that the type and intensity of the RSET was a determinant of the systemic inflammatory response. Supplementation with a nutraceutical blend containing SOD has been shown to be beneficial in humans, resulting in an improvement in the velocity at which lactate threshold is reached during intense exercise [30]; however this was not seen in the present study.

Elevated PEAK CK values in the present study are comparable to those of horses having engaged in racing and training regimes intense enough to induce overtraining syndrome [57]. Exercise-induced increases in CK in the present study may indicate increased myocyte membrane permeability [58], which was not attenuated by SOD supplementation. Increases in CK have also been positively correlated with increases in ROS formation and subsequent increases in lipid peroxidation in horses $[11,59,60]$. Therefore, it is plausible that exercise-induced increases in ROS may influence myocyte membrane permeability permitting the muscle enzymes to enter circulation [61]. Creatine kinase was also positively correlated with IFN $\gamma$ and IL-10 in the current study, suggesting that changes in myocyte integrity, resulting from exercise and increased ROS production, coincide with a pro-inflammatory immune response. 
Systemic Inflammatory Response. Increases in pro-inflammatory cytokine transcripts at PEAK and sample times following the RSET indicate a pro-inflammatory response to exercise and a counter anti-inflammatory response. These physiological changes are most likely in response to incurred tissue microdamage, increased ROS generation, and possibly mild endotoxemia following the intense, exhaustive exercise test, although direct measurements of neutrophilia and circulating endotoxin were not quantified in the present study.

Positive correlations detected between the cytokines evaluated in the present study further illustrate the close relationships between these cytokines. For example, IFN $\gamma$ is considered a pro-inflammatory cytokine that serves to activate macrophages, augment the synthesis of other pro-inflammatory cytokines, and induce nitric oxide synthase and ROS formation $[49,62]$. The pro-inflammatory response also signals anti-inflammatory cytokines, such as IL-10, which is also thought to possess antioxidant properties. Interleukin-10 inhibits several cytokines including IFN $\gamma$, IL- $1 \beta$, TNF $\alpha$, and IL- 6 , mainly by initiating the degradation of mRNA for these cytokines as well as the inhibition of antigen presentation $[63,64]$ and release of ROS [65]. The inhibition of proinflammatory cytokines, NO production, and superoxide anion formation in endothelial tissue [66], can have an impact on neutrophil priming for oxidative burst [67]. Furthermore, antioxidants have been show to upregulate IL-10 in antigen-IgE-activated mast cells in vitro [68].

Changes in Antioxidant Status. In the present study, changes in SOD activity, GPx activity, GSH-T, and a reduction in plasma NO concentrations were detected, indicating that the RSET was effective in eliciting changes in antioxidant defenses and is indirectly suggestive of exercise-induced oxidative stress, although direct analysis of oxidative stress biomarkers was not performed. The authors speculate that increases in SOD, GPx, and GSH-T at PEAK were compensatory responses to exercise-induced oxidative stress in the current study. Several studies have demonstrated similar exercise-induced changes in antioxidant status or oxidative stress after a single bout of intense exercise in humans [69$71]$ and horses [9, 12, 56, 72-75], and following a bout of prolonged intense exercise in horses $[10,60]$.

Alterations in SOD, GPx, and GSH-T in response to exercise vary within the literature. With regard to the current study, GPx and GSH-T were positively correlated and increased as the mares were fatiguing at the end of the RSET. This increase in the antioxidant enzyme and its thiol substrate is in accordance with previous studies reporting similar increases in SOD, GPx, and GSH-T in horses [59, 74], GSH-T and GPx in rat muscle [76], and GSH-T in human plasma [77], either during or following strenuous exercise. Elevations in antioxidant defenses indirectly suggest that the exercise stress increased ROS production. Increased SOD activity suggests generation of superoxide anions, and the increases in GPx and GSH-T indicates increased production, most likely from the metabolism of superoxide by SOD, and subsequent elimination of hydrogen peroxide via oxygenation of reduced glutathione, in the present study. Furthermore, GSH-T and CK were positively correlated in the present study, as has been reported previously [60], suggesting that increasing ROS formation may be altering muscle membrane integrity allowing for increases in circulating muscle enzymes and antioxidant defenses.

In contrast to the present study's findings, several other studies reported no changes in erythrocyte GPx or GSH-T [12] relative to an acute bout of exercise in horses, reduced erythrocyte GPx activity, and no changes in SOD activity in trained Thoroughbred horses following intense exercise on a race track $\left(1000 \mathrm{~m}\right.$ at $15 \mathrm{~m} \mathrm{~s}^{-1} ;$ [78]). Decreases in GPx and GSH-T in endurance horses following an $80 \mathrm{~km}$ race [79] and a $140 \mathrm{~km}$ race [10] have also been reported. It should be noted that the exercise modalities, exercise intensities, duration, and fitness status of the experimental models differ from study to study, and comparison between studies should be made with this in mind. Interestingly, in a majority of the studies that did not report changes in antioxidant defenses, the experimental subjects were exercise trained and fit for their respective exercise test, indicating that antioxidant systems most likely adapt to the specific conditions of regular training [80].

The decrease in plasma NO concentration, along with upregulation of cytokine transcripts following exercise, was comparable to responses noted in previous reports in horses following a single bout of intense exhaustive exercise, with the exception of $\mathrm{TNF} \alpha$ and IL- 6 transcripts remaining unchanged, in the present study $[6,81]$. The decline in NO may be due to increased utilization, increased excretion, and decreased production or bioavailability of NO resulting from increased oxidative stress, in the present study. Plasma NO was positively correlated with pro-inflammatory cytokines IFN $\gamma$ and TNF $\alpha$ and negatively correlated with GPx in the present study. The inverse relationship of NO to GPx may reflect the increase in ROS and subsequent decrease in NO bioavailability, in conjunction with increased GPx to counter oxidative stress. Exercise-induced generation of superoxide and NO lends to the formation of peroxynitrite a damaging reactive nitrogen species, therefore, reducing NO bioavailability [82]. The positive association of NO with proinflammatory cytokines most likely reflects the postexercise decline in IFN $\gamma$ and NO in the present study, indicating recovery from exercise-induced inflammation and increased utilization or depletion of NO.

Implications on Joint Health. Healthy articular cartilage serves to distribute load in a pain and friction-free manner. Cartilage consists of specialized cells (chondrocytes) distributed in three distinct layers within an intracellular matrix consisting primarily of proteoglycans and type II collagen [83]. The integrity of the matrix is dependent on chondrocyte metabolism, which has been shown to be influenced by stressors, including shear and compressive strain, which occur with exercise [83]. One study, using normal human and bovine articular chondrocyte culture, demonstrated that fluid-induced shear stimulated glycosaminoglycan (GAG) 
synthesis, and after $48 \mathrm{~h}$ of shear stress $\mathrm{PGE}_{2}$ production was increased when compared to controls [84]. Furthermore, evidence of ROS (specifically superoxide anion) in the joint has been reported [85]. Presence of ROS in joints can lead to proteoglycan cleavage [86], compromising the integrity of the cartilage matrix. The relative increase in $\mathrm{PGE}_{2}$ from PRE to $24 \mathrm{~h}$ POST in the exercise trial suggests a slightly delayed onset of inflammation following the RSET. It is plausible that the type of joint loading resulting from the RSET in the current study induced enough fluid-induced shear and change in hydrostatic pressure gradient, to induce a delayed increase in $\mathrm{PGE}_{2}$ relative to PRE concentrations. Elevated concentrations of $\mathrm{PGE}_{2}$ have previously been shown to occur in inflamed and osteoarthritic joint tissues of horses [22, $38,51,87,88]$. Furthermore, these elevated prostaglandins may compromise the cartilage matrix by decreasing proteoglycan content $[89,90]$ as well as initiating a localized pain response via sensitization of peripheral nociceptor terminals [20]. In a previous study, increases in circulating proinflammatory cytokine transcripts (interleukin-1 beta) were detected $2 \mathrm{~h}$ following intense exhaustive treadmill exercise [6]. Interleukin-1 beta is a regulator of $\mathrm{PGE}_{2}$ release from joint tissues, which may also help explain why the increase in $\mathrm{PGE}_{2}$ is delayed past the $2 \mathrm{~h}$ POST sample in the current study. It is unknown if this was a transient increase, or if $\mathrm{PGE}_{2}$ levels remained elevated for a sustained period of time as sampling was not carried out past $24 \mathrm{~h}$ POST. The resting and postexercise $\mathrm{PGE}_{2}$ concentrations were higher in the current study compared to previous reports in horses [22], which might be attributable to different analytical techniques (extraction of $\mathrm{PGE}_{2}$ from $\mathrm{SF}$ versus evaluation of concentrations in diluted synovial fluid).

The increase in synovial fluid concentrations of CS at 30 min POST, which declined back to pre-exercise levels by $2 \mathrm{~h}$ POST in the exercise trial, suggests a transient increase in aggrecan synthesis. The magnitude of change from pre- to postexercise samples in the exercise trial was similar to that reported in chronically exercised horses [22]. Furthermore, absolute concentrations of CS in the present study were lower than those reported in the same chronically exercised healthy horses and in horses with clinical osteoarthritis [22]. When magnitude of change from $T_{2}$ to $T_{4}$ and $2 \mathrm{~h}$ POST to $24 \mathrm{~h}$ POST were compared between the preliminary and exercise trials, respectively, the increase in CS was 2.6 times greater in the exercise trial. Furthermore, absolute concentrations of CS were approximately $2057 \mathrm{ng} \mathrm{mL}^{-1}$ higher for the $2 \mathrm{~h}$ POST sample in the exercise trial compared to the $T_{2}$ sample in the preliminary trial. This data suggests that the RSET did elicit changes in cartilage turnover, most likely in response to cyclic high compressive loading [91-95]. Several other studies have reported exercise-induced changes in cartilage metabolism. At the end of a 6 wk training study in horses, investigators reported an increase in newly synthesized proteoglycan from an ex vivo cartilage culture when compared to cartilage from nonexercised controls [96]. Another study reported a decrease in aggrecan synthesis and concomitant increase in decorin synthesis in equine cartilage explants that persisted for $16 \mathrm{wks}$ of rest following $17 \mathrm{wks}$ of strenuous exercise [97]. Increases in CS and keratin sulfate (catabolic marker of cartilage metabolism) have been associated with cases of osteochondral fragmentation in horses [24] and repetitive exercise over time $[22,98]$. Healthy horses seem to be able to return to homeostatic conditions in joint tissues fairly quickly as was the case in the present study. However, if this modality and intensity of exercise were repeated over time without sufficient recovery periods, it could result in a chronic degenerative state, ultimately compromising the stability and functionality of the articular cartilage. Although it is difficult to determine whether the increase in synovial fluid CS concentrations at $24 \mathrm{~h}$ POST in the exercise trial is an artifact of repeated arthrocentesis, as was identified in the preliminary study, or a response to exercise, the possibility that the delayed increase in $\mathrm{PGE}_{2}$ following exercise may have contributed to the mild increase in aggrecan turnover, should not be completely discounted. Significant associations between serum and synovial fluid biomarkers of cartilage metabolism have been reported [22]; however, the same associations were not detected in the exercise trial.

Synovial fluid concentrations of both $\mathrm{PGE}_{2}$ and CS were higher in hock joints when compared to carpal joints in the exercise trial. This finding is in accord with a previous study which found higher concentration of nitric oxide in hock joints compared to that of carpus samples from mature healthy Standardbred mares [6]. The differences between hock and carpus joints in the present study may be attributable to conformational and biomechanical features unique to Standardbred trotters or pacers, with a higher degree of dynamic compressive and shear stress occurring in the hock joints. Another study also demonstrated increased nitric oxide synthesis in response to shear stress in bovine articular chondrocytes in culture, which in turn mediated an increase in GAG synthesis [99]. It has previously been reported [100] that $14.3 \%$ of 753 young Standardbred trotters sampled were diagnosed with osteochondrosis in the tibiotarsal joint and $11.8 \%$ were diagnosed with bony fragments in the palmar/plantar portion of the metacarpo and metatarsophalangeal joints. These data provide further evidence that Standardbreds, compared to other breeds, experience more exercise-induced stress in the hock joints compared to joints in the forelimbs and should be considered in light of athletic conditioning and rehabilitation programs.

4.3. Effect of Nutritional Supplementation. It was hypothesized that SOD supplementation in horses would mirror the beneficial findings reported in the literature demonstrating oral bioavailability $[29,30,101]$ and subsequent benefits including anti-inflammatory $[102,103]$, antioxidant $[104,105]$, and chondroprotective properties $[34,106,107]$ reported in several other animal models. Data from a porcine ischemia reperfusion injury model [105] and a human hyperbaric oxygen oxidative stress model [108] suggested that supplementation of a vegetal preparation of SOD combined with a wheat-gliadin biopolymer (SOD/gliadin) is protective against oxidative DNA damage and decreases markers of lipid peroxidation in circulation. Mice supplemented with SOD/gliadin for $28 \mathrm{~d}$ showed a rise in 
circulating antioxidant enzyme activity which was positively correlated with an increased erythrocyte resistance to oxidative induced hemolysis. This study also found increases in hepatic antioxidant defenses which were correlated with a significant decrease in hepatocyte apoptosis in the presence of Sin-1 (peroxynitrite chemical donor) when compared to controls [29]. In another study, peritoneal macrophages activated by an intraperitoneal injection of IFN $\gamma$, collected from mice after a 28 day supplementation of SOD/gliadin, and stimulated with IgG1IC ex vivo, exhibited a reduction in TNF $\alpha$ production and elevated IL-10 production as well as decreased superoxide, NO, and peroxynitrite concentrations [102].

In human studies, supplementation of SOD/gliadin in soccer athletes has been shown to reduce oxidative stress. Specifically, a decrease in the magnitude of 8 -iso PGF $2 \alpha$ response was observed in the experimental group following a graded step-wise exhaustive treadmill exercise test [30]. Similarly, college football athletes supplemented with a proprietary nutraceutical drink blend containing SOD, coenzyme Q10 and beta glucans during a 7-wk training period demonstrated anti-inflammatory (reduced IL-6), antioxidant (reduced 8-iso PGF2 $\alpha$ ), and less muscle membrane leakage of CK both after acute and chronic bouts of exercise compared to nonsupplemented controls [103]. Lastly, in patients with HIV or AIDs exhibiting compromised antioxidant status, it was determined that SOD/gliadin $\left(1000 \mathrm{IU} \mathrm{d}^{-1}\right)$ supplementation for $3 \mathrm{wks}$ normalized the patients' circulating SOD activity and total antioxidant status (TAS), demonstrating that oral supplementation with vegetal SOD supplement can improve systemic antioxidant defenses [104]. A previous study examining aspects of joint health demonstrated that addition of SOD to bovine synovial fluid was protective against hyaluronic acid depolymerization by superoxide derived hydroxyl radicals in vitro, thereby preserving the viscoelastic properties characteristic of healthy synovial fluid [106]. Palosein (generic name Orgotein), an FDA-approved, injectable form of a $\mathrm{Cu}-\mathrm{Zn}$ protein with high-SOD enzyme activity derived from bovine liver [33], has also been shown to ameliorate free radical-induced (superoxide) loss in synovial fluid viscosity in horses [34]. Contrary to these reports, data from the present study suggest that supplemental SOD has no effect on biomarkers of inflammatory response, antioxidant status, or joint health in an equine exercise model.

Several factors may have contributed to the ineffectiveness of SOD supplementation in equine exercise model used in the exercise trial. The SOD may not have been effectively delivered to the target tissue, or the enzyme activity may have been compromised in the digestive and/or absorption processes. Historically, intravenous administration of SOD was the most common route of delivery, but therapeutic capabilities were limited due to its short half-life of less than $30 \mathrm{~min}$ [109]. Oral administration of SOD is a newer practice and the use of delivery technologies is a growing area of interest. The gliadin coating used in the present study is a hydrophobic gliadin-biopolymer demonstrated to be an effective carrier for oral delivery of active food ingredients, specifically lipophilic molecules [110]. Gliadin biopolymer has been shown to enhance oral pharmacology of SOD [111] delaying enzyme release thereby preserving the enzyme activity throughout the gastrointestinal (GI) tract as well as purportedly increasing intestinal permeability via increased zonulin release which opens the enterocyte tight junctions $[112,113]$. It has been demonstrated that the SOD enzyme requires protection during GI transit [29]. Failure of SOD efficacy in the present study may be due to the gliadin biopolymer releasing the active ingredient at an inappropriate time during GI transit, rendering it incapable of being absorbed into circulation. Previous studies have investigated the biodegradation of Gliadin bioadhesion properties, pharmacokinetic properties, and active ingredient stability of various products $[114,115]$. Subsequent studies should take these into consideration for the target species studied.

Failure of the oral SOD formulation to elicit increases in erythrocyte SOD activity may have been due to dosing rate. In the present study, $3000 \mathrm{IU} \mathrm{d}^{-1} \mathrm{SOD}$ was fed at an average rate of $5.84 \pm 0.18 \mathrm{IU} \mathrm{kg} \mathrm{bw}^{-1} \mathrm{~d}^{-1}$ to the research mares. A similar SOD preparation was fed to pigs at rates of 0.316 and $1.2 \mathrm{IU} \mathrm{kg} \mathrm{bw}^{-1} \mathrm{~d}^{-1}$ which allegedly resulted in $25 \%$ and $41 \%$ increases in plasma SOD activity, respectively [116]. In dogs, SOD has been supplemented at the rate of approximately $10 \mathrm{IU} \mathrm{kg} \mathrm{bw}^{-1} \mathrm{~d}^{-1}$ [116], and mice have received SOD supplement at the rate of $0.003 \mathrm{IU} \mathrm{kg} \mathrm{bw}^{-1} \mathrm{~d}^{-1}$ [29]. Although the horses in the present study were fed at a substantially higher rate than the other species, this dose could be insufficient and future research in horses should investigate different supplementation rates in excess of $3000 \mathrm{IU} \mathrm{d}^{-1}$.

Furthermore, an unfit animal model was thought to be more susceptible to tissue microdamage, inflammation, and oxidative stress resulting from the RSET compared to that of a physically fit model conditioned to a specific modality of exercise. This unfit model theoretically would have experienced the greatest benefit from SOD supplementation when compared to a fit, conditioned individual who might be better able to cope with exercise-induced ROS formation and inflammation, as previously demonstrated in horses and humans $[30,56,117,118]$. Despite their healthy but unfit status, endogenous antioxidant defenses of the horses used in the present study appear to have been sufficient to handle the magnitude of oxidant stress relative to the RSET, therefore, rendering any benefits of exogenous SOD supplementation undetectable.

\section{Conclusion}

Repeated arthrocentesis within a $48 \mathrm{~h}$ time frame did not seem to influence $\mathrm{PGE}_{2}$ whereas CS concentrations did increase in joints of healthy mature horses in the present study. Therefore, impact of sampling techniques, exclusive to any treatment effects, should be evaluated and considered in the experimental design and subsequent data interpretation. Fluctuations in biomarkers of inflammation, antioxidant status, or aggrecan synthesis were not altered by SOD supplementation in Standardbred mares having 
undergone intense exercise in the present study. The RSET did result in a proinflammatory response as well as upregulated antioxidant defenses, which suggests that it is an appropriate exercise modality for investigating systemic inflammatory responses and antioxidant status and oxidative stress in horses. The use of intense treadmill exercise to induce inflammation provides a realistic yet controlled, repeatable, and relatively noninvasive model of inflammation and joint metabolism under dynamic physiologic stress. The inflammatory and metabolic changes detected in synovial fluid in the exercise trial are thought to be normal physiological responses to a single bout of intense exercise. These data suggest that joint health in mature healthy horses is not compromised following a single intense bout of exhaustive exercise. However, repetitive exercise at this intensity, without sufficient recovery periods could result in sustained localized joint inflammation resulting in a chronic degenerative state. Oral supplements may provide practical solutions to support optimal health, performance, and the prevention of chronic disease in a variety of athletic species. Despite previous evidence of SOD efficacy in other species, further investigation is needed to elucidate benefit(s) of SOD supplementation and effective supplement delivery technologies in horses.

\section{Acknowledgments}

The authors would like to acknowledge the New Jersey Agricultural Experiment Station State Equine Initiative for partial funding of this study as well as the Rutgers University Animal Science Department undergraduate student research group and Animal Care staff. Lastly, a special thanks are due to Dr. Elizabeth O'Byrne (Rutgers University), Dr. David Horohov (University of Kentucky, Gluck Equine Research Center), Dr. Amy O. Burk and Tim Shellem (University of Maryland), and Drs. Michael Orth and Cara Robison (Michigan State University) for their help with sample analysis.

\section{References}

[1] D. E. Auer, J. C. Ng, J. Hrdlicka, and A. A. Seawright, "The elimination of injected superoxide dismutase from synovial fluid of the horse," Australian Veterinary Journal, vol. 66, no. 4, pp. 117-119, 1989.

[2] A. L. Bertone, J. L. Palmer, and J. Jones, "Synovial fluid cytokines and eicosanoids as markers of joint disease in horses," Veterinary Surgery, vol. 30, no. 6, pp. 528-538, 2001.

[3] H. H. Petersen, J. P. Nielsen, and P. M. H. Heegaard, "Application of acute phase protein measurements in veterinary clinical chemistry," Veterinary Research, vol. 35, no. 2, pp. 163-187, 2004.

[4] E. C. Firth, "The response of bone, articular cartilage and tendon to exercise in the horse," Journal of Anatomy, vol. 208, no. 4, pp. 513-526, 2006.

[5] J. M. Streltsova, K. H. McKeever, N. R. Liburt et al., "Effect of orange peel and black tea extracts on markers of performance and cytokine markers of inflammation," Equine and Comparative Exercise Physiology, vol. 2006, pp. 121-130, 2006.
[6] E. D. Lamprecht, C. A. Bagnell, and C. A. Williams, "Inflammatory responses to three modes of intense exercise in Standardbred mares-A pilot study," Comparative Exercise Physiology, vol. 5, pp. 115-125, 2009.

[7] J. D. Lang, P. J. McArdle, P. J. O'Reilly, and S. Matalon, "Oxidant-antioxidant balance in acute lung injury," Chest, vol. 122, no. 6, pp. 314S-320S, 2002.

[8] N. Ishida, S. Hobo, T. Takahashi et al., "Chronological changes in superoxide-scavenging ability and lipid peroxide concentration of equine serum due to stress from exercise and transport," Equine Veterinary Journal. Supplement, vol. 30, pp. 430-433, 1999.

[9] A. White, M. Estrada, K. Walker et al., "Role of exercise and ascorbate on plasma antioxidant capacity in thoroughbred race horses," Comparative Biochemistry and Physiology, vol. 128, no. 1, pp. 99-104, 2001.

[10] D. J. Marlin, K. Fenn, N. Smith et al., "Changes in circulatory antioxidant status in horses during prolonged exercise," Journal of Nutrition, vol. 132, no. 6, pp. 1622S-1627S, 2002.

[11] C. A. Williams, D. S. Kronfeld, T. M. Hess, K. E. Saker, and P. A. Harris, "Lipoic acid and vitamin E supplementation to horses diminishes endurance exercise induced oxidative stress, muscle enzyme leakage, and apoptosis. Page 105 in The Elite Race and Endurance Horse," in Proceedings of the Equine Sports Medicine and Science, A. Lindner, Ed., Oslo, Norway, 2004.

[12] S. Kinnunen, S. Hyyppä, A. Lehmuskero et al., "Oxygen radical absorbance capacity (ORAC) and exercise-induced oxidative stress in trotters," European Journal of Applied Physiology, vol. 95, no. 5-6, pp. 550-556, 2005.

[13] P. N. Shek, B. H. Sabiston, A. Buguet, and M. W. Radomski, "Strenuous exercise and immunological changes: a multipletime-point analysis of leukocyte subsets, CD4/CD8 ratio, immunoglobulin production and NK cell response," International Journal of Sports Medicine, vol. 16, no. 7, pp. 466-474, 1995.

[14] I. K. M. Brenner, V. M. Natale, P. Vasiliou, A. I. Moldoveanu, P. N. Shek, and R. J. Shephard, "Impact of three different types of exercise on components of the inflammatory response," European Journal of Applied Physiology and Occupational Physiology, vol. 80, no. 5, pp. 452-460, 1999.

[15] P. D. Rossdale, R. Hopes, N. J. Digby, and K. offord, "Epidemiological study of wastage among racehorses 1982 and 1983," Veterinary Record, vol. 116, no. 3, pp. 66-69, 1985.

[16] J. A. Kidd, C. Fuller, and A. R. S. Barr, "Osteoarthritis in the horse," Equine Veterinary Education, vol. 13, no. 3, pp. 160$168,2001$.

[17] USDA, Lameness and Laminitis in U.S. Horses. USDA: APHIS:VS, CEAH, National Animal Health Monitoring System. \#N348.1001 USDA, Fort Collins, Colo, USA, 2001.

[18] P. K. Dyson, B. F. Jackson, D. U. Pfeiffer, and J. S. Price, "Days lost from training by two- and three-year-old Thoroughbred horses: a survey of seven UK training yards," Equine Veterinary Journal, vol. 40, no. 7, pp. 650-657, 2008.

[19] B. von Rechenberg, C. W. McIlwraith, M. K. Akens, D. D. Frisbie, C. Leutenegger, and J. A. Auer, "Spontaneous production of nitric oxide (NO), prostaglandin (PGE2) and neutral metalloproteinases (NMPs) in media of explant cultures of equine synovial membrane and articular cartilage from normal and osteoarthritic joints," Equine Veterinary Journal, vol. 32, no. 2, pp. 140-150, 2000.

[20] E. V. Tchetina, J. A. Di Battista, D. J. Zukor, J. Antoniou, and A. R. Poole, "Prostaglandin PGE2 at very low concentrations suppresses collagen cleavage in cultured human 
osteoarthritic articular cartilage: this involves a decrease in expression of proinflammatory genes, collagenases and COL10A1, a gene linked to chondrocyte hypertrophy," Arthritis Research and Therapy, vol. 9, no. 4, article R75, 2007.

[21] C. W. McIlwraith, "Use of synovial fluid and serum biomarkers in equine bone and joint disease: a review," Equine Veterinary Journal, vol. 37, no. 5, pp. 473-482, 2005.

[22] D. D. Frisbie, F. Al-Sobayil, R. C. Billinghurst, C. E. Kawcak, and C. W. McIlwraith, "Changes in synovial fluid and serum biomarkers with exercise and early osteoarthritis in horses," Osteoarthritis and Cartilage, vol. 16, no. 10, pp. 1196-1204, 2008.

[23] A. R. Poole, M. Ionescu, A. Swan, and P. A. Dieppe, "Changes in cartilage metabolism in arthritis are reflected by altered serum and synovial fluid levels of the cartilage proteoglycan aggrecan. Implications for pathogenesis," Journal of Clinical Investigation, vol. 94, no. 1, pp. 25-33, 1994.

[24] D. D. Frisbie, C. S. Ray, M. Ionescu, A. R. Poole, P. L. Chapman, and C. W. McIlwraith, "Measurement of synovial fluid and serum concentrations of the 846 epitope of chondroitin sulfate and of carboxy propeptides of type II procollagen for diagnosis of osteochondral fragmentation in horses," American Journal of Veterinary Research, vol. 60, no. 3, pp. 306-309, 1999.

[25] L. A. Fortier, "Systemic therapies for joint disease in horses," Veterinary Clinics of North America, vol. 21, no. 3, pp. 547$557,2005$.

[26] S. K. Nelson, S. K. Bose, G. K. Grunwald, P. Myhill, and J. M. McCord, "The induction of human superoxide dismutase and catalase in vivo: a fundamentally new approach to antioxidant therapy," Free Radical Biology and Medicine, vol. 40, no. 2, pp. 341-347, 2006.

[27] S. Cuzzocrea, E. Mazzon, L. Dugo, A. P. Caputi, D. P. Riley, and D. Salvemini, "Protective effects of M40403, a superoxide dismutase mimetic, in a rodent model of colitis," European Journal of Pharmacology, vol. 432, no. 1, pp. 79-89, 2001.

[28] E. Masini, S. Cuzzocrea, E. Mazzon, C. Marzocca, P. F. Mannaioni, and D. Salvemini, "Protective effects of M40403, a selective superoxide dismutase mimetic, in myocardial ischaemia and reperfusion injury in vivo," British Journal of Pharmacology, vol. 136, no. 6, pp. 905-917, 2002.

[29] I. Vouldoukis, M. Conti, P. Krauss et al., "Supplementation with gliadin-combined plant superoxide dismutase extract promotes antioxidant defences and protects against oxidative stress," Phytotherapy Research, vol. 18, no. 12, pp. 957-962, 2004.

[30] S. M. Arent, P. Davitt, D. L. Golem, C. A. Williams, K. H. McKeever, and C. Jaouhari, "The effects of a post-workout nutraceutical drink on body composition, performance and hormonal and biochemical responses in Division I college football players," Comparative Exercise Physiology, vol. 6, pp. 73-80, 2009.

[31] S. M. Arent, J. K. Pellegrino, C. A. Williams, D. A. Difabio, and J. C. Greenwood, "Nutritional supplementation, performance, and oxidative stress in college soccer players," Journal of Strength and Conditioning Research, vol. 24, no. 4, pp. 1117-1124, 2010.

[32] M. Petelin, Z. Pavlica, T. Ivanuša, M. Šentjurc, and U. Skalerič, "Local delivery of liposome-encapsulated superoxide dismutase and catalase suppress periodontal inflammation in beagles," Journal of Clinical Periodontology, vol. 27, no. 12, pp. 918-925, 2000.

[33] W. Huber, "Orgotein-(bovine Cu-Zn superoxide dismutase), an anti-inflammatory protein drug: discovery, toxicology and pharmacology," European Journal of Rheumatology and Inflammation, vol. 4, no. 2, pp. 173-182, 1981.

[34] D. E. Auer, J. C. Ng, and A. A. Seawright, "Effect of palosein (superoxide dismutase) and catalase upon oxygen derived free radical induced degradation of equine synovial fluid," Equine Veterinary Journal, vol. 22, no. 1, pp. 13-17, 1990.

[35] American Association of Equine Practitioners, Guide for Veterinary Service and Judging of Equestrian Events, 4th edition, 1991.

[36] D. R. Henneke, G. D. Potter, J. L. Kreider, and B. F. Yeates, "Relationship between condition score, physical measurements and body fat percentage in mares," Equine Veterinary Journal, vol. 15, no. 4, pp. 371-372, 1983.

[37] R. G. Westervelt, J. R. Stouffer, H. F. Hintz, and H. F. Schryver, "Estimating fatness in horses and ponies," Journal of Animal Science, vol. 43, pp. 781-785, 1976.

[38] R. Y. Au, T. K. Al-Talib, A. Y. Au, P. V. Phan, and C. G. Frondoza, "Avocado soybean unsaponifiables (ASU) suppress TNF- $\alpha$, IL- $1 \beta$, COX-2, iNOS gene expression, and prostaglandin E2 and nitric oxide production in articular chondrocytes and monocyte/macrophages," Osteoarthritis and Cartilage, vol. 15, no. 11, pp. 1249-1255, 2007.

[39] C. Beauchamp and I. Fridovich, "Superoxide dismutase: improved assays and an assay applicable to acrylamide gels," Analytical Biochemistry, vol. 44, no. 1, pp. 276-287, 1971.

[40] P. M. Graham-Thiers, D. S. Kronfeld, K. A. Kline, D. J. Sklan, and P. A. Harris, "Dietary protein and fat effects on protein status in arabian horses during interval training and repeated sprints," Journal of Equine Veterinary Science, vol. 23, no. 12, pp. 554-559, 2003.

[41] J. A. Wilson, D. S. Kronfeld, L. S. Gay, J. H. Williams, T. M. Wilson, and M. I. Lindinger, "Sarcoplasmic reticulum responses to repeated sprints are affected by conditioning of horses," Journal of Animal Science, vol. 76, no. 12, pp. 30653071, 1998.

[42] K. Hasegawa, S. Wakino, S. Tatematsu et al., "Role of asymmetric dimethylarginine in vascular injury in transgenic mice overexpressing dimethylarginie dimethylaminohydrolase 2," Circulation Research, vol. 101, no. 2, pp. e2-e10, 2007.

[43] R. J. Cybulski, P. Sanz, F. Alem, S. Stibitz, R. L. Bull, and A. D. O'Brien, "Four superoxide dismutases contribute to Bacillus anthracis virulence and provide spores with redundant protection from oxidative stress," Infection and Immunity, vol. 77, no. 1, pp. 274-285, 2009.

[44] Z. Qin, M. Karabiyikoglu, Y. Hua et al., "Hyperbaric oxygeninduced attenuation of hemorrhagic transformation after experimental focal transient cerebral ischemia," Stroke, vol. 38, no. 4, pp. 1362-1367, 2007.

[45] F. M. Maiorino, R. Brigelius-Flohé, K. D. Aumann, A. Roveri, D. Schomburg, and L. Flohé, "Diversity of glutathione peroxidases," Methods in Enzymology, vol. 252, pp. 38-53, 1995.

[46] J. P. Richie, L. Skowronski, P. Abraham, and Y. Leutzinger, "Blood glutathione concentrations in a large-scale human study," Clinical Chemistry, vol. 42, no. 1, pp. 64-70, 1996.

[47] M. M. Vick, A. A. Adams, B. A. Murphy et al., "Relationships among inflammatory cytokines, obesity, and insulin sensitivity in the horse," Journal of Animal Science, vol. 85, no. 5, pp. 1144-1155, 2007.

[48] K. J. Livak and T. D. Schmittgen, "Analysis of relative gene expression data using real-time quantitative PCR and the 2$\Delta \Delta$ CT method," Methods, vol. 25, no. 4, pp. 402-408, 2001.

[49] D. M. Ainsworth, J. A. Appleton, S. W. Eicker, R. Luce, M. J. Flaminio, and D. F. Antczak, "The effect of strenuous exercise 
on mRNA concentrations of interleukin-12, interferongamma and interleukin-4 in equine pulmonary and peripheral blood mononuclear cells," Veterinary Immunology and Immunopathology, vol. 91, no. 1, pp. 61-71, 2003.

[50] C. Ramakers, J. M. Ruijter, R. H. Lekanne Deprez, and A. F. M. Moorman, "Assumption-free analysis of quantitative realtime polymerase chain reaction (PCR) data," Neuroscience Letters, vol. 339, no. 1, pp. 62-66, 2003.

[51] R. van den Boom, C. H. A. van de Lest, S. Bull, P. A. J. Brama, P. R. van Weeren, and A. Barneveld, "Influence of repeated arthrocentesis and exercise on synovial fluid concentrations of nitric oxide, prostaglandin $\mathrm{E}_{2}$ and glycosaminoglycans in healthy equine joints," Equine Veterinary Journal, vol. 37, no. 3, pp. 250-256, 2005.

[52] P. A. J. Brama, R. van den Boom, J. DeGroot, G. H. Kiers, and P. R. van Weeren, "Collagenase-1 (MMP-1) activity in equine synovial fluid: influence of age, joint pathology, exercise and repeated arthrocentesis," Equine Veterinary Journal, vol. 36, no. 1, pp. 34-40, 2004.

[53] R. van den Boom, P. A. J. Brama, G. H. Kiers, J. DeGroot, A. Barneveld, and P. R. Van Weeren, "The influence of repeated arthrocentesis and exercise on matrix metalloproteinase and tumour necrosis factor $\alpha$ activities in normal equine joints," Equine Veterinary Journal, vol. 36, no. 2, pp. 155-159, 2004.

[54] F. C. Robion, B. Doizé, L. Bouré et al., "Use of synovial fluid markers of cartilage synthesis and turnover to study effects of repeated intra-articular administration of methylprednisolone acetate on articular cartilage in vivo," Journal of Orthopaedic Research, vol. 19, no. 2, pp. 250-258, 2001.

[55] A. Szucsik, V. Baliskonis, and K. H. McKeever, "Effect of seven common supplements on plasma electrolyte and total carbon dioxide concentration and strong ion difference in Standardbred horses subjected to a simulated race test," Equine and Comparative Exercise Physiology, vol. 3, pp. 3744, 2006.

[56] C. A. Williams, M. E. Gordon, C. L. Betros, and K. H. McKeever, "Apoptosis and antioxidant status are influenced by age and exercise training in horses," Journal of Animal Science, vol. 86, no. 3, pp. 576-583, 2008.

[57] B. Padalino, G. Rubino, P. Centoducati, and F. Petazzi, "Training versus overtraining: evaluation of two protocols," Journal of Equine Veterinary Science, vol. 27, no. 1, pp. 28-31, 2007.

[58] P. A. Harris, "Musculoskeletal disease," in Equine Internal Medicine, S. M. Reed and W. M. Bayly, Eds., pp. 375-397, WB Saunders, 1998.

[59] A. Frankiewicz-Jóźko and E. Szarska, "Anti-oxidant level to exercise in the blood of endurance horses," Biology of Sport, vol. 17, no. 3, pp. 217-227, 2000.

[60] C. A. Williams, D. S. Kronfeld, T. M. Hess et al., "Comparison of oxidative stress and antioxidant status in endurance horses in three $80-\mathrm{km}$ races," Equine and Comparative Exercise Physiology, vol. 2, pp. 153-157, 2004.

[61] J. M. McBride and W. J. Kraemer, "Effect of vitamin E status on lipid peroxidation in exercised horses," The Journal of Strength \& Conditioning Research, vol. 13, pp. 175-183, 1999.

[62] A. I. Moldoveanu, R. J. Shephard, and P. N. Shek, "The cytokine response to physical activity and training," Sports Medicine, vol. 31, no. 2, pp. 115-144, 2001.

[63] J. J. Haddad and C. S. Fahlman, "Redox- and oxidantmediated regulation of interleukin-10: an anti-inflammatory, antioxidant cytokine?" Biochemical and Biophysical Research Communications, vol. 297, no. 2, pp. 163-176, 2002.
[64] A. Oberholzer, C. Oberholzer, and L. L. Moldawer, "Interleukin-10: a complex role in the pathogenesis of sepsis syndromes and its potential as an anti-inflammatory drug," Critical Care Medicine, vol. 30, no. 1, pp. S58-S63, 2002.

[65] R. Pezzilli, P. Billi, R. Miniero, and B. Barakat, "Serum interleukin-10 in human acute pancreatitis," Digestive Diseases and Sciences, vol. 42, no. 7, pp. 1469-1472, 1997.

[66] C. A. Gunnett, D. D. Heistad, D. J. Berg, and F. M. Faraci, "IL10 deficiency increases superoxide and endothelial dysfunction during inflammation," American Journal of Physiology, vol. 279, no. 4, pp. H1555-H1562, 2000.

[67] M. A. Gougerot-Podicalo, C. Elbim, and S. Chollet-Martin, "Modulation by pro- and anti-inflammatory cytokines of the oxidative burst of human neutrophils," Pathologie Biologie, vol. 44, no. 1, pp. 36-41, 1996.

[68] S. S. Chen, J. Gong, L. F-T, and U. Mohammed, "Naturally occurring polyphenolic antioxidants modulate IgE-mediated mast cell activation," Immunology, vol. 100, no. 4, pp. 471480, 2000.

[69] Y. Hong, S. Hong, Y. H. Chang, and S. H. Cho, "Influence of an orally effective superoxide dismutase (Glisodin) on strenuous exercise-induced changes of blood antioxidant enzymes and plasma lactate," in Proceedings of the American Association for Clinical Chemistry. National Meeting-Poster, Los Angeles, Calif, USA, 2004.

[70] R. J. Bloomer, "Effect of exercise on oxidative stress biomarkers," Advances in Clinical Chemistry, vol. 46, pp. 1-50, 2008.

[71] H. Andersson, A. Karlsen, R. Blomhoff, T. Raastad, and F. Kadi, "Plasma antioxidant responses and oxidative stress following a soccer game in elite female players," Scandinavian Journal of Medicine and Science in Sports, vol. 20, no. 4, pp. 600-608, 2010.

[72] P. C. Mills, "Effects of exercise intensity and environmental stress on indices of oxidative stress and iron homeostasis during exercise in the horse," European Journal of Applied Physiology and Occupational Physiology, vol. 74, no. 1-2, pp. 60-66, 1996.

[73] E. Chiaradia, L. Avellini, F. Rueca et al., "Physical exercise, oxidative stress and muscle damage in racehorses," Comparative Biochemistry and Physiology B, vol. 119, no. 4, pp. 833836, 1998.

[74] C. A. Williams and S. A. Carlucci, "Oral vitamin E supplementation on oxidative stress, vitamin and antioxidant status in intensely exercised horses," Equine Veterinary Journal. Supplement, no. 36, pp. 617-621, 2006.

[75] D. C. Donovan, C. A. Jackson, P. T. Colahan et al., "Assessment of exercise-induced alterations in neutrophil function in horses," American Journal of Veterinary Research, vol. 68, no. 11, pp. 1198-1204, 2007.

[76] Li Li Ji and R. Fu, "Responses of glutathione system and antioxidant enzymes to exhaustive exercise and hydroperoxide," Journal of Applied Physiology, vol. 72, no. 2, pp. 549-554, 1992.

[77] K. Sahlin, K. Ekberg, and S. Cizinsky, "Changes in plasma hypoxanthine and free radical markers during exercise in man," Acta Physiologica Scandinavica, vol. 142, no. 2, pp. 275281, 1991.

[78] K. Ono, K. Inui, T. Hasegawa et al., "The changes of antioxidative enzyme activities in equine erythrocytes following exercise," The Japanese Journal of Veterinary Science, vol. 52, no. 4, pp. 759-765, 1990.

[79] B. J. Hargreaves, D. S. Kronfeld, J. N. Waldron et al., "Antioxidant status of horses during two $80-\mathrm{km}$ endurance 
races," Journal of Nutrition, vol. 132, no. 6, pp. 1781S-1783S, 2002.

[80] A. M. Niess, H. H. Dickhuth, H. Northoff, and E. Fehrenbach, "Free radicals and oxidative stress in exerciseimmunological aspects," Exercise Immunology Review, no. 5, pp. 22-56, 1999.

[81] D. C. Donovan, C. A. Jackson, P. T. Colahan, N. Norton, and D. J. Hurley, "Exercise-induced alterations in proinflammatory cytokines and prostaglandin F2 $\alpha$ in horses," Veterinary Immunology and Immunopathology, vol. 118, no. 3-4, pp. 263-269, 2007.

[82] A. Sureda, P. Tauler, A. Aguiló et al., "Blood cell NO synthesis in response to exercise," Nitric Oxide, vol. 15, no. 1, pp. 5-12, 2006.

[83] R. L. Smith, M. C. D. Trindade, T. Ikenoue et al., "Effects of shear stress on articular chondrocyte metabolism," Biorheology, vol. 37, no. 1-2, pp. 95-107, 2000.

[84] R. L. Smith, B. S. Donlon, M. K. Gupta et al., "Effects of fluid-induced shear on articular chondrocyte morphology and metabolism in vitro," Journal of Orthopaedic Research, vol. 13, no. 6, pp. 824-831, 1995.

[85] A. N. Dimock, P. D. Siciliano, and C. W. Mcilwraith, "Evidence supporting an increased presence of reactive oxygen species in the diseased equine joint," Equine Veterinary Journal, vol. 32, no. 5, pp. 439-443, 2000.

[86] R. A. Greenwald and W. W. Moy, "Inhibition of collagen gelation by action of the superoxide radical," Arthritis and Rheumatism, vol. 22, no. 3, pp. 251-259, 1979.

[87] S. May, R. Hooke, and K. Peremans, "Prostaglandin E2 in equine joint disease," Vlaams Diergeneeskundig Tijdschrift, vol. 63, no. 6, pp. 187-191, 1994.

[88] P. S. Chan, J. P. Caron, G. J. M. Rosa, and M. W. Orth, "Glucosamine and chondroitin sulfate regulate gene expression and synthesis of nitric oxide and prostaglandin E2 in articular cartilage explants," Osteoarthritis and Cartilage, vol. 13, no. 5, pp. 387-394, 2005.

[89] C. C. Teitz and O. D. Chrisman, "The effect of salicylate and chloroquine on prostaglandin induced articular damage in the rabbit knee," Clinical Orthopaedics, vol. 108, pp. 264-274, 1975.

[90] L. Lippiello, K. Yamamoto, D. Robinson, and H. J. Mankin, "Involvement of prostaglandins from rheumatoid synovium in inhibition of articular cartilage metabolism," Arthritis and Rheumatism, vol. 21, no. 8, pp. 909-917, 1978.

[91] M. J. Palmoski and K. D. Brandt, "Effects of static and cyclic compressive loading on articular cartilage plugs in vitro," Arthritis and Rheumatism, vol. 27, no. 6, pp. 675-681, 1984.

[92] R. L. Y. Sah, Y. J. Kim, J. Y. H. Doong, A. J. Grodzinsky, A. H. K. Plaas, and J. D. Sandy, "Biosynthetic response of cartilage explants to dynamic compression," Journal of Orthopaedic Research, vol. 7, no. 5, pp. 619-636, 1989.

[93] J. J. Parkkinen, J. Ikonen, M. J. Lammi, J. Laakkonen, M. Tammi, and H. J. Helminen, "Effects of cyclic hydrostatic pressure on proteoglycan synthesis in cultured chondrocytes and articular cartilage explants," Archives of Biochemistry and Biophysics, vol. 300, no. 1, pp. 458-465, 1993.

[94] M. D. Buschmann, Y. J. Kim, M. Wong, E. Frank, E. B. Hunziker, and A. J. Grodzinsky, "Stimulation of aggrecan synthesis in cartilage explants by cyclic loading is localized to regions of high interstitial fluid flow," Archives of Biochemistry and Biophysics, vol. 366, no. 1, pp. 1-7, 1999.

[95] E. H. Frank, M. Jin, A. M. Loening, M. E. Levenston, and A. J. Grodzinsky, "A versatile shear and compression apparatus for mechanical stimulation of tissue culture explants," Journal of Biomechanics, vol. 33, no. 11, pp. 1523-1527, 2000.

[96] J. L. Palmer, A. L. Bertone, C. J. Malemud, B. G. Carter, R. S. Papay, and J. Mansour, "Site-specific proteoglycan characteristics of third carpal articular cartilage in exercised and nonexercised horses," American Journal of Veterinary Research, vol. 56, no. 12, pp. 1570-1576, 1995.

[97] C. B. Little, P. Ghosh, and R. Rose, "The effect of strenuous versus moderate exercise on the metabolism of proteoglycans in articular cartilage from different weight-bearing regions of the equine third carpal bone," Osteoarthritis and Cartilage, vol. 5, no. 3, pp. 161-172, 1997.

[98] M. Okumura, G. H. Kim, M. Tagami, S. Haramaki, and T. Fujinaga, "Serum Keratan sulphate as a cartilage metabolic marker in horses: the effect of exercise," Journal of Veterinary Medicine A, vol. 49, no. 4, pp. 195-197, 2002.

[99] P. Das, D. J. Schurman, and R. L. Smith, "Nitric oxide and $G$ proteins mediate the response of bovine articular chondrocytes to fluid-induced shear," Journal of Orthopaedic Research, vol. 15, no. 1, pp. 87-93, 1997.

[100] A. M. Grøndahl and N. I. Dolvik, "Heritability estimations of osteochondrosis in the tibiotarsal joint and of bony fragments in the palmar/plantar portion of the metacarpoand metatarsophalangeal joints of horses," Journal of the American Veterinary Medical Association, vol. 203, no. 1, pp. 101-104, 1993

[101] C. B. Webb, T. L. Lehman, and K. W. McCord, "Effects of an oral superoxide dismutase enzyme supplementation on indices of oxidative stress, proviral load, and CD4:CD8 ratios in asymptomatic FIV-infected cats," Journal of Feline Medicine and Surgery, vol. 10, no. 5, pp. 423-430, 2008.

[102] I. Vouldoukis, D. Lacan, C. Kamate et al., "Antioxidant and anti-inflammatory properties of a Cucumis melo LC. extract rich in superoxide dismutase activity," Journal of Ethnopharmacology, vol. 94, no. 1, pp. 67-75, 2004.

[103] S. M. Arent, J. Pellegrino, K. H. McKeever et al., "Nutritional supplementation, body composition, performance, and hormonal responses in division I college football players," Medicine and Science in Sports and Exercise. Supplement, vol. 5, p. S361, 2007.

[104] H. Chenal, A. Davit-Spraul, J. Brevet et al., "The effects of an orally effective SOD on AIDS West African patients in a randomized double-blinded clinical study," in Proceedings of the XVI International AIDS Conference, no. CDB0865, Toronto, Canada, 2006.

[105] J. Kick, B. Hauser, H. Bracht et al., "Effects of a cantaloupe melon extract/wheat gliadin biopolymer during aortic crossclamping," Intensive Care Medicine, vol. 33, no. 4, pp. 694702, 2007.

[106] J. M. McCord, "Free radicals and inflammation: protection of synovial fluid by superoxide dismutase," Science, vol. 185, no. 4150 , pp. 529-531, 1974.

[107] W. H. Betts and L. G. Cleland, "Effect of metal chelators and antiinflammatory drugs on the degradation of hyaluronic acid," Arthritis and Rheumatism, vol. 25, no. 12, pp. 14691476, 1982.

[108] C. M. Muth, Y. Glenz, M. Klaus, P. Radermacher, G. Speit, and X. Leverve, "Influence of an orally effective SOD on hyperbaric oxygen-related cell damage," Free Radical Research, vol. 38, no. 9, pp. 927-932, 2004.

[109] A. Baret, G. Jadot, and A. M. Michelson, "Pharmacokinetic and anti-inflammatory properties in the rat of superoxide dismutases (Cu SODs and Mn SOD) from various species," 
Biochemical Pharmacology, vol. 33, no. 17, pp. 2755-2760, 1984.

[110] M. A. Arangoa, M. A. Campanero, M. J. Renedo, G. Ponchel, and J. M. Irache, "Gliadin nanoparticles as carriers for the oral administration of lipophilic drugs. Relationships between bioadhesion and pharmacokinetics," Pharmaceutical Research, vol. 18, no. 11, pp. 1521-1527, 2001.

[111] B. Dugas, "Glisodin: a nutraceutical product that promotes the oral delivery of superoxide dismutase," Free Radical Biology and Medicine, vol. 33, p. S64, 2002.

[112] M. G. Clemente, S. De Virgiliis, J. S. Kang et al., "Early effects of gliadin on enterocyte intracellular signalling involved in intestinal barrier function," Gut, vol. 52, no. 2, pp. 218-223, 2003.

[113] S. Drago, R. El Asmar, M. Di Pierro et al., "Gliadin, zonulin and gut permeability: effects on celiac and non-celiac intestinal mucosa and intestinal cell lines," Scandinavian Journal of Gastroenterology, vol. 41, no. 4, pp. 408-419, 2006.

[114] V. Stella, P. Vallée, P. Albrecht, and E. Postaire, "Gliadin films. I: preparation and in vitro evaluation as a carrier for controlled drug release," International Journal of Pharmaceutics, vol. 121, no. 1, pp. 117-121, 1995.

[115] M. A. Arangoa, G. Ponchel, A. M. Orecchioni, M. J. Renedo, D. Duchêne, and J. M. Irache, "Bioadhesive potential of gliadin nanoparticulate systems," European Journal of Pharmaceutical Sciences, vol. 11, no. 4, pp. 333-341, 2000.

[116] Personal Communication, Dr. David Griffin, Nutramax Laboratories, Edgewood, Md, USA, 2012.

[117] S. K. Powers, L. L. Ji, and C. Leeuwenburgh, "Exercise training-induced alterations in skeletal muscle antioxidant capacity: a brief review," Medicine and Science in Sports and Exercise, vol. 31, no. 7, pp. 987-997, 1999.

[118] C. Kasapis and P. D. Thompson, "The effects of physical activity on serum C-reactive protein and inflammatory markers: a systematic review," Journal of the American College of Cardiology, vol. 45, no. 10, pp. 1563-1569, 2005. 


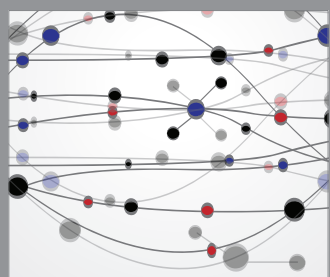

The Scientific World Journal
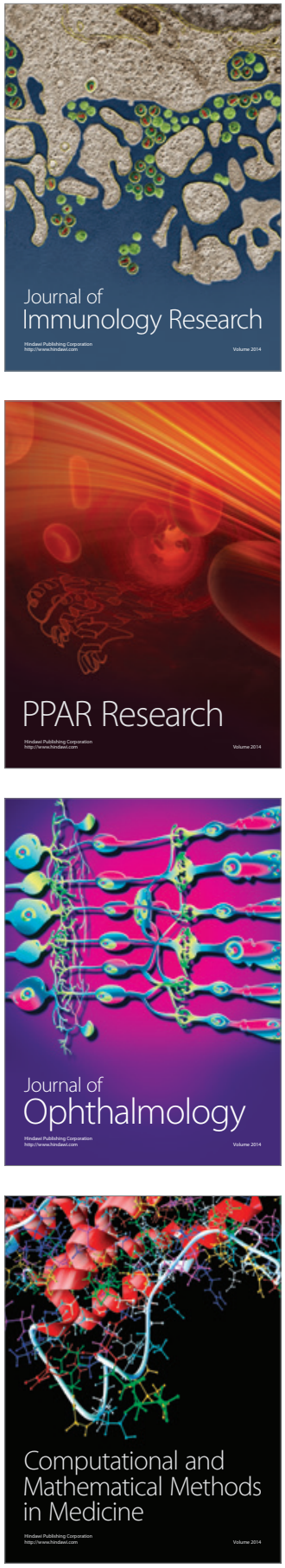

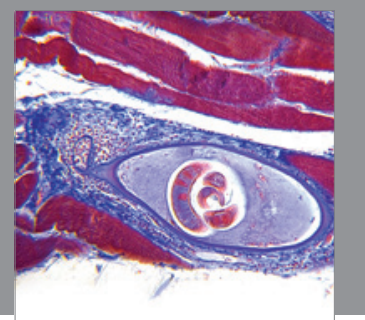

Gastroenterology

Research and Practice
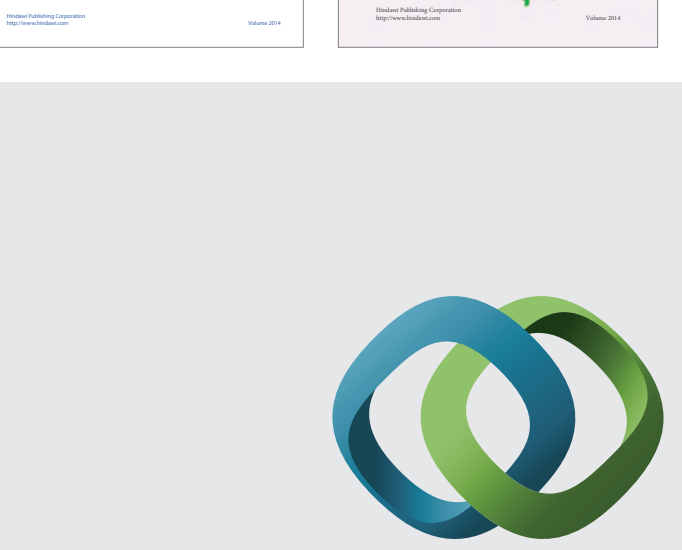

\section{Hindawi}

Submit your manuscripts at

http://www.hindawi.com
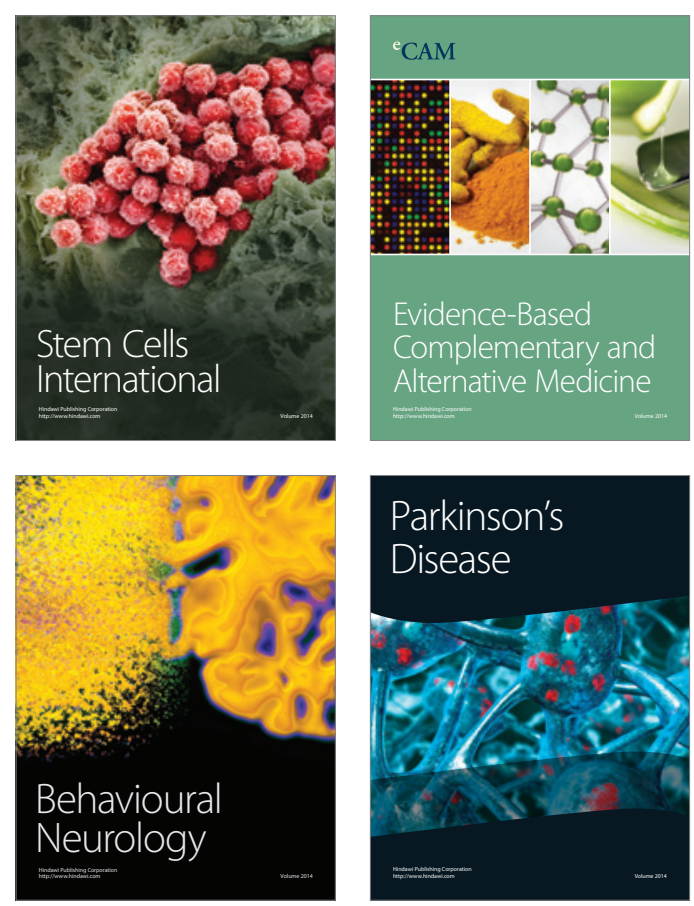

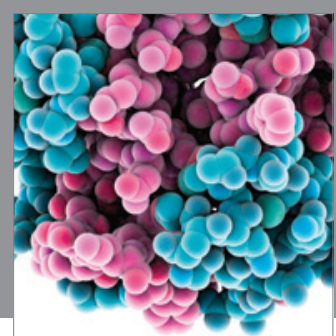

Journal of
Diabetes Research

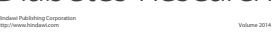

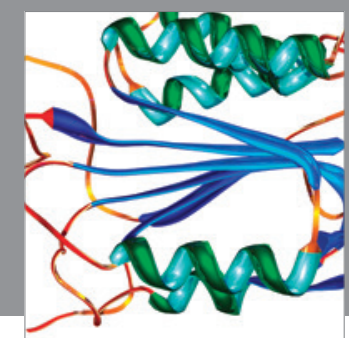

Disease Markers
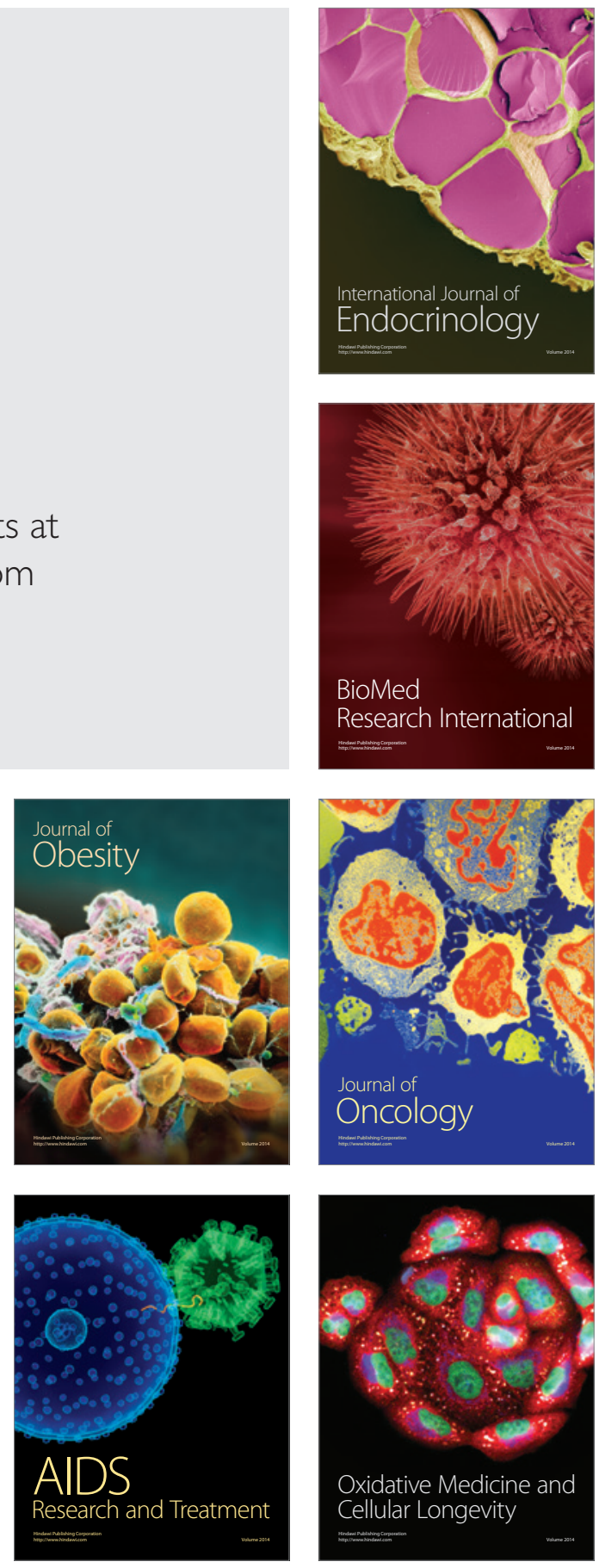